\title{
Latis: A Spatial Decision Support System to Assess Low-Impact Site Development Strategies
}

\author{
G. Wayne Wilkerson, ${ }^{1}$ William H. McAnally, ${ }^{2}$ James L. Martin, ${ }^{2}$ Jeff A. Ballweber, \\ Kim Collins Pevey, ${ }^{4}$ Jairo Diaz-Ramirez, ${ }^{4}$ and Austin Moore ${ }^{1}$ \\ ${ }^{1}$ Department of Landscape Architecture, C117 Landscape Architecture Building, Mississippi State, MS 39762, USA \\ ${ }^{2}$ Department of Civil and Environmental Engineering, 222 Walker Hall, Mississippi State, MS 39762, USA \\ ${ }^{3}$ Pickering Firm Inc., 460 Briarwood Dr., Suite 515, Jackson, MS 601/956-3663, USA \\ ${ }^{4}$ Department of Civil and Environmental Engineering, Mississippi State, MS 39762, USA
}

Correspondence should be addressed to William H. McAnally, mcanally@cee.msstate.edu

Received 8 July 2009; Accepted 10 February 2010

Academic Editor: Kirk Hatfield

Copyright ( 2010 G. Wayne Wilkerson et al. This is an open access article distributed under the Creative Commons Attribution License, which permits unrestricted use, distribution, and reproduction in any medium, provided the original work is properly cited.

Significant advances have been made in the use of spatial and hydrologic models to quantify the impact of Best Management Practices (BMPs) and Low-Impact Development (LID) practices on water quality. Further advances are the goal of this work to add selection of BMP/LID and calculation of implementation costs, all integrated into a spatial decision support system (DSS). The Hydrologic Simulation Program in FORTRAN (HSPF), an unsteady flow model, was combined with links to desktop spatial data analysis tools, a spreadsheet listing BMP/LID and their implementation, operation, and maintenance cost data. Testing of the DSS, named Latis, allowed improvements in direct design of BMP, and a survey of landscape and engineering practitioners provided the impetus for a simplified version, Latis-LIDIA.

\section{Introduction}

Commercial, industrial, and residential development is increasingly challenged to minimize disruption of the natural hydrologic regime to promote sustainability and comply with environmental regulations. In particular, site plans are being evaluated based on their water quality and quantity impacts on a watershed scale. Site development plans that maintain the hydrologic regime and sustain water quality downstream are consistent with the approach described as smart growth or low-impact development. Significant advances have been made in the use of spatial models, including geographical information systems (GISs) and sophisticated hydrologic models, to assess the impact of potential development. Similarly, experience with Best Management Practices (BMPs) provides good insight into how various management practices such as stormwater detention and vegetated areas contribute to improved water quality. The Tennessee Valley Authority (TVA), Environmental Protection Agency (EPA), Mississippi Department of Environmental Quality, and Mississippi State University encourage the use of low-impact/smart growth strategies and want to make their application rapid and easy. The work described here is intended to advance that goal.

1.1. Objectives. This work was performed to develop Decision Support System (DSS) tools that will allow users to balance watershed protection with smart growth/low-impact site development strategies. Specifically, the objective is a DSS that will

(i) predict time-varying runoff and water quality as a function of rainfall, site characteristics, and Best Management Practices (BMPs) for development sites within the Southeastern U.S;

(ii) calculate BMP cost,

(iii) allow various scenarios to be compared for effectiveness and cost, 
(iv) be GIS-based or CAD-based for input queries and for output displays,

(v) run on a desktop computer,

(vi) be in the public domain to the maximum extent possible.

The purpose of this paper is to present a version of the desired DSS, called Latis, and to describe its initial applications and generation of a simplified version, LatisLIDIA. (Latis is the Celtic goddess of clean water and ale.)

1.2. Hydrologic Decision Support. Available hydrologic evaluation tools range from simple empirical methods, such as "curve number" calculations of total runoff [1], to sophisticated, physics-based numerical models of timevarying discharge, such as GSSHA [2]. Singh and Woolhiser [3] provide a thorough review of this range of tools, which experienced practitioners can use to evaluate the effect of land use changes on runoff and sometimes water quality. Hydrologic decision support requires combining these runoff estimates with displays of results, comparison with design standards and costs, so that the most effective and efficient solutions are identified. The best known, most widely used decision support system is EPA's Better Assessment Science Integrating Point and Nonpoint Sources (BASINS) [4]. The authors applied a screen to the available hydrologic and decision support tools, using the bullet requirements listed above in Part 1 to select the components of Latis.

\section{Latis Components}

2.1. Hydrologic Model. A hydrologic model representing rainfall and runoff processes is an essential component of the system. Available hydrologic models include those that are continuous or event based, distributed or lumped, and empirical or physical $[3,5,6]$. Texas A\&M University and the U.S. Bureau of Reclamation developed a hydrologic modeling inventory website of 79 models to date [7].

The Hydrological Simulation Program-FORTRAN (HSPF) model $[8,9]$ was selected as most likely to satisfy this project's requirements. HSPF computes the movement of water through a complete hydrologic cycle-rainfall, interception, evapotranspiration, runoff, infiltration, and flow through the ground-and the associated transport of constituents with that flow. Water quality constituents simulated by HSPF include dissolved oxygen, biochemical oxygen demand, temperature, pesticides, conservatives, fecal coliforms, sediment detachment and transport, sediment routing nitrate, organic nitrogen, orthophosphate, organic phosphorus, phytoplankton, and zooplankton. HSPF is divided into three application modules and five utility modules. Application modules simulate the runoff and water quality processes in pervious areas (PERLANDs), impervious areas (IMPLNDs), and during routing through reservoir and reaches (RCHRES) [9]. Time series (e.g., meteorological and flow observed data) are accessed, manipulated, and analyzed in the utility modules.
The modeled area must be delineated in homogeneous land areas called Hydrologic Response Units (HRUs). For each HRU, the combination of weather, soil, land use, and topographic and geologic properties is unique, giving rise to a "semidistributed" model structure. HRUs can be impervious or pervious areas which are modeled independently. Each HRU requires input data such as rainfall, temperature, potential evapotranspiration, and parameters related to land use, soil characteristics, and agricultural practices to simulate hydrology, sediments, nutrients, and pesticides [9]. Through use of a mostly undocumented feature, outputs from an HRU can be exported to an adjacent HRU or reach an essential capability for evaluating successive BMP on a site. That approach, used here, is essential for designing specific BMP and is not available in other public domain software.

The first version of HSPF was released in 1980, while Version 12.2 is the most recent, which is packaged with Version 4.0 of EPA's Better Assessment Science Integrating Point and Nonpoint Sources-BASINS [1]. BASINS is an integrated system of models and tools for performing water quality analyses of watersheds. It uses an open-source GIS called MapWindow. Some versions of HSPF can be run in standalone mode, but the EPA-supported version is run through a BASINS interface, WinHSPF [1]. WinHSPF runs under Microsoft Windows with a graphical user interface for input, model execution, and output displays. The interface is fairly straightforward but did not support all the features of HSPF that were needed for evaluating site development at the time the work was initiated. In its place, a simplified Windows interface was adopted as described below.

Extensive and successful applications of HSPF components (hydrology, erosion, sediment transport, and instream water quality) in urban and rural areas around the world have been reported (see $[10,11]$ for HSPF applications, review, and citations). The model has been applied to a huge spatial size range from a few hectares up to $128,000 \mathrm{~km}^{2}$ (Chesapeake Bay).

Deterministic and stochastic evaluations of the HSPF model have been reported (e.g., [11]), which are a distinct advantage in presenting results to the public and regulatory agencies.

Deterministic evaluations are defined as a unique set of input data and parameter values yielding a unique model output. Conversely, in a stochastic evaluation, randomness is present, and input time series as parameter values are described by probability distributions, which yield random model outputs. Certainty bounds can be calculated using random model outputs. Stochastic model evaluations are useful to evaluate, for instance, sensitivity of model parameters and parameter uncertainty propagation into model results. While the HSPF model has been extensively and successfully tested in different countries since 1980, less work has been done to quantify the effect of land cover datasets, spatial scale, evapotranspiration bias, rainfall spatial variability, channel hydraulic variability, and parameter uncertainty on model results. Diaz-Ramirez [11] evaluated propagation of spatial rainfall variability, channel hydraulic variability, and model parameter uncertainty into HSPF streamflow simulations in a rural watershed located in Alabama and 
Mississippi. He found that parameter uncertainty was still more important than those sources of uncertainty accomplished in this study.

2.2. BMP Selection Tools and Data Assessment. A review of available data and guidance on BMP characteristics, removal efficiencies, and costs was conducted in order to evaluate the applicability of available data and guidance. For the comparisons of effectiveness and costs within the selected modeling framework, three types of information were required: removal efficiencies, costs, and rates of infiltration. The relevant information was compiled in a Microsoft Excel spreadsheet for use.

There are a number of reports and databases that compile results of BMP studies (e.g., the International Stormwater Best Management Practices Database, ISBMPD [12]). However, in many cases these reports and databases either have limited information on removal efficiencies of contaminants of interest or include such a wide range of removal efficiencies as to be of limited use. For example, in the ISMPMD, which compiled information from over 200 studies conducted during the past 15 years, nitrogen data are compiled and reported in six forms (nitrate plus nitrite nitrogen, ammonia nitrogen, Kjeldhal Nitrogen, Organic Nitrogen Dissolved, Organic Nitrogen Particulate, and Total Nitrogen). The database contains only 13 records for Total Nitrogen removal efficiencies (for all BMPs surveyed) that ranged from -47 to +62 percent. Similarly, five forms of phosphorus were tabulated with 22 records for Total Phosphorus removal efficiencies (for all BMPs surveyed) that ranged from -84 to +80 percent. In addition, among sources surveyed, there are considerable inconsistencies in the terminology used to define particular BMP and the methodologies used to determine the cost and effectiveness of those BMPs. Significant new research is underway on BMP effectiveness; however, consistent with EPA and legal requirements, only published, widely used removal rates are employed in Latis.

For the initial Latis development effort, four sources of information were identified which contained sufficient and relevant information, for the purposes of this project, regarding the design and removal efficiencies of BMP. These sources included the

(1) U.S. Department of Transportation, Federal Highway Administration, Stormwater Best Management Practices in an Ultra-Urban Setting: Selection and Monitoring [13],

(2) U.S. Environmental Protection Agency, National Pollution Discharge Elimination System, PostConstruction Storm Water Management in New Development \& Redevelopment, BMP Fact Sheets [14],

(3) Atlanta Regional Commission, Georgia Stormwater Management Manual, Volume 2: Technical Handbook [15],

(4) Best Management Practices for South Florida Urban Stormwater Management Systems [16].
Of the above, the Georgia Stormwater Manual was the most complete and applicable. In addition, a variety of sources were surveyed which provided information regarding the costs associated with BMP implementation. Cost information sources were surveyed to provide a minimum, maximum, and average cost associated with construction of a particular BMP, as well as a cost formulation where applicable. Information from these sources was added to the BMP database. While there are a number of current research studies on BMP effectiveness, use of those results in a practical database such as Latis must be deferred until they have been published by one of these authoritative sources, otherwise the results may not be used in legal proceedings under the Daubert Rule [17].

2.3. BMP Database. Information on BMP removal efficiencies, costs, and rates of infiltration is subdivided into five spreadsheet worksheets, each of which is briefly described below.

The Selection worksheet is the main working sheet for BMP assessments. The Selection worksheet is subdivided into three parts. Part A of the worksheet (see Figure 1) includes a list box that allows the user to select a specific BMP for further analysis. Once the user selects the BMP, the information compiled on that BMP is presented. The information provided includes a range of removal efficiencies for the following water quality constituents: Total Suspended Solids, Total Phosphorus, Total Nitrogen, Nitrate-Nitrogen, Metals, Bacteria, Oil and Grease, and Total Petroleum Hydrocarbons (TPHs). Information on the construction and maintenance costs for the selected BMP is provided as low, high, and average values and as a unit cost where applicable.

Part A of the Selection worksheet is intended to allow users to rapidly screen the costs and effectiveness of specific BMP. For model implementation, specific values of BMP removal efficiencies and costs must be determined, which requires a more detailed analysis. To aid in this analysis, Part $\mathrm{B}$ of the Selection worksheet (see Figure 2) includes links to embedded files for specific BMP from each of the three sources cited. Since there were inconsistencies in terminology among the sources, the original names for specific BMP were retained from each of these sources and grouped into like types. The user can select a specific BMP type and review guidance from each of these sources in order to aid in the final design and selection of a BMP and in determination of removal efficiencies and costs. The cell entries in Figure 2 are hyperlinks which call up Adobe document (pdf) files describing the BMP and their design features, so that the user can evaluate them for possible use.

The second worksheet is the Removal Data Table (Figure 3). The table is provided for more detailed information on specific BMP removal efficiencies and is the basis for the information included in Part A of the Selection worksheet. For example, the first entry in Figure 3 is an infiltration trench, which is expected to remove 75 to 99 percent of Total Suspended Solids (TSSs), as shown in column C, 55 to 75 percent of Total Phosphorous (TP) as shown in column D, and so on. Drop down menus for each 


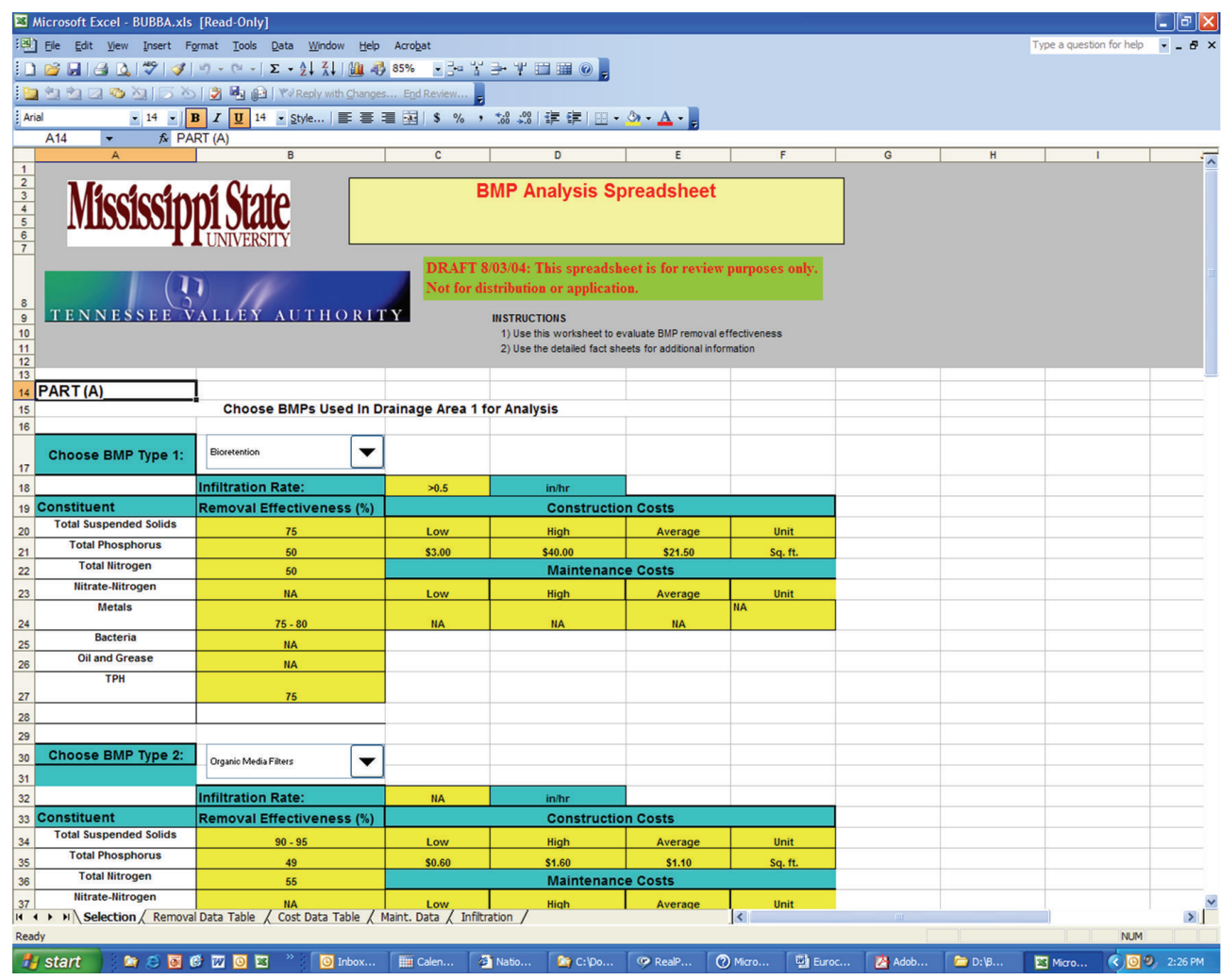

FIgure 1: Part A of the Selection worksheet.

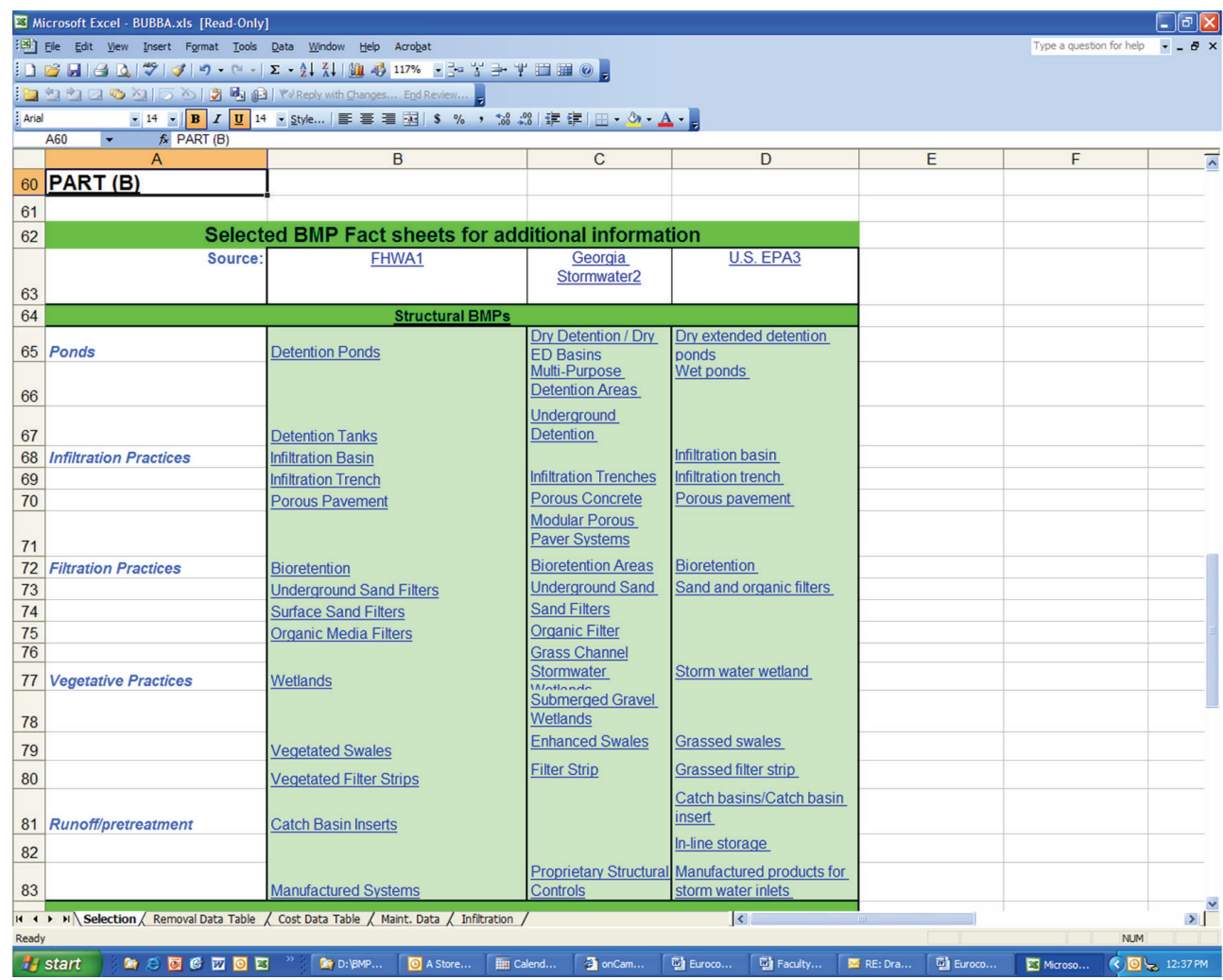

Figure 2: Part B of the Selection worksheet. 


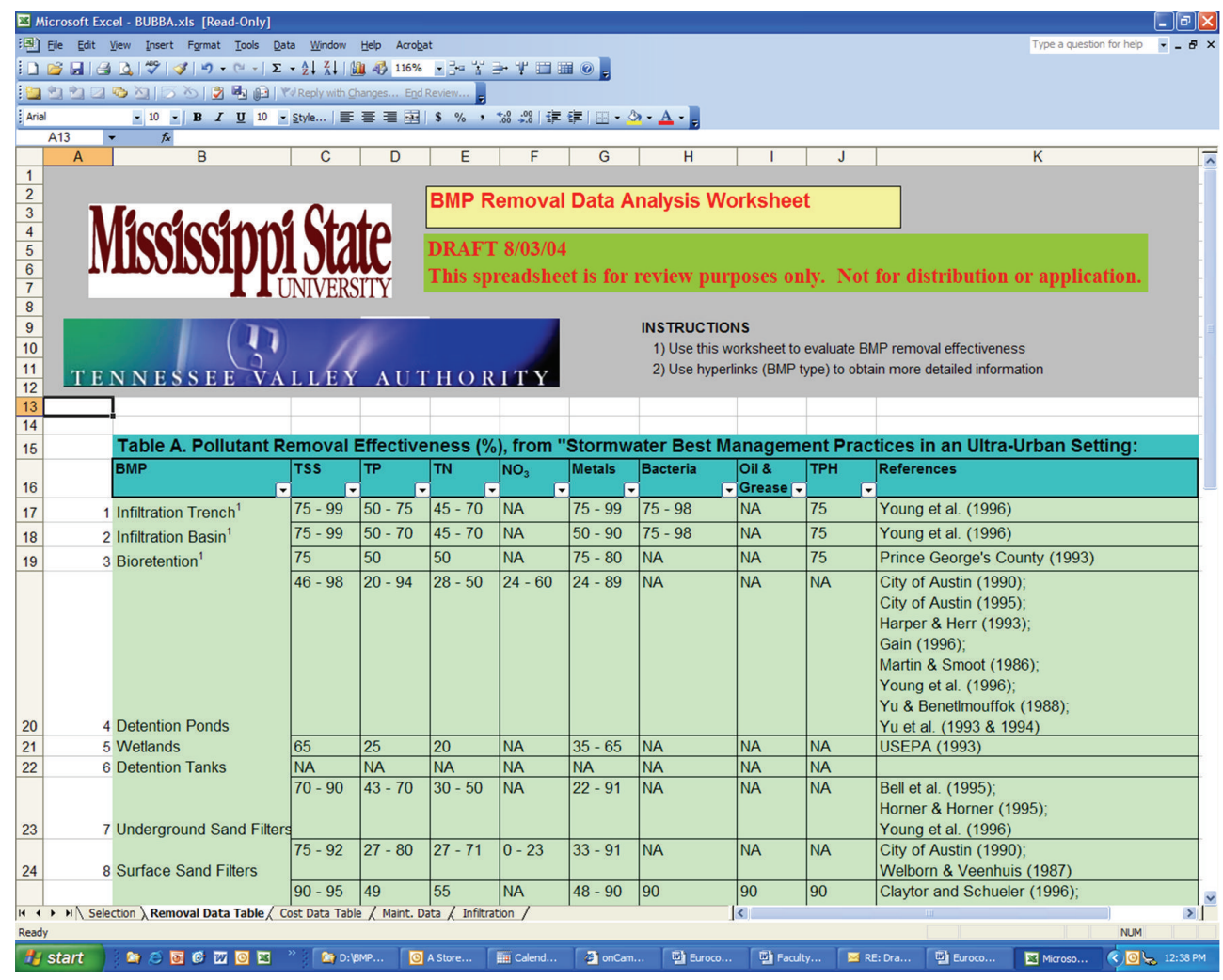

Figure 3: Removal Data Table worksheet.

column allow the user to rapidly sort BMP or water quality constituents. References and links are provided for the source of the tabulated information.

The third worksheet is the Cost Data Table (Figure 4). This worksheet provides more detailed cost information and is the basis for the summary information in Part A of the Selection worksheet. For example, the first entry in Figure 4, the infiltration trench, is known to cost $\$ 2.50$ to $\$ 7.91$ per $\mathrm{ft}^{3}\left(0.028 \mathrm{~m}^{3}\right)$. (English units are used because they are dominant in the U.S. construction community). References and hyperlinks are provided for each source of cost information so that the user can easily check for updated values.

The fourth worksheet is the Maintenance Data Table (Figure 5). This worksheet provides more detailed maintenance information and is the basis for the summary information in Part A of the Selection worksheet. For example, the infiltration entry in Figure 5 shows that the average annual maintenance cost ranges from 5 percent to 20 percent of the initial construction cost. The initial cost (Figure 4) and maintenance cost (Figure 5) can be used together to estimate life cycle costs for each alternative in order to select the most efficient form of BMP. References and links are again provided for each source of BMP maintenance information.

The fifth and final worksheet is the Infiltration Data Table (Figure 6). This worksheet provides more detailed information on available infiltration data and is the basis for the summary information in Part A of the Selection worksheet. For example, the infiltration trench is shown to exhibit infiltration rates ranging from 0.5 to 3 inches per hour. The information is based on a limited survey and needs to be refined in subsequent development phases but can be used to refine BMP selections when groundwater recharge is a particular concern and to choose infiltration rates in the hydrologic evaluation phase.

2.4. Integrating BMP Data with a User Interface. BASINS 3.1, which was used by HSPF at the time of the original testing, requires both ESRI ArcView and Spatial Analyst. For these reasons, ArcView was selected as the original GIS interface to test for integrating with the BMP cost data. ArcView is not delivered with an extension that will calculate area required for the HSPF model analysis. Area values are also required for costing BMP scenarios. A search was made of the ESRI knowledge base [18] and a suitable extension identified. More than one extension may be found on the WEB site, but the one used as part of this project is simply called Area Tools. This file was downloaded to the workstation used for testing and installed in the proper ArcView directory $\left(\backslash E S R I \backslash A V \_G I S 30 \backslash A R C V I E W \backslash E X T 32\right)$. When the ArcView project is open the extension may be selected and an icon will pop up on the menu bar.

Each ArcView theme is comprised of four files, one of them being a database file where attributes about the theme are maintained. When the BMP theme is first created no area column exists. When the BMP theme is selected and 


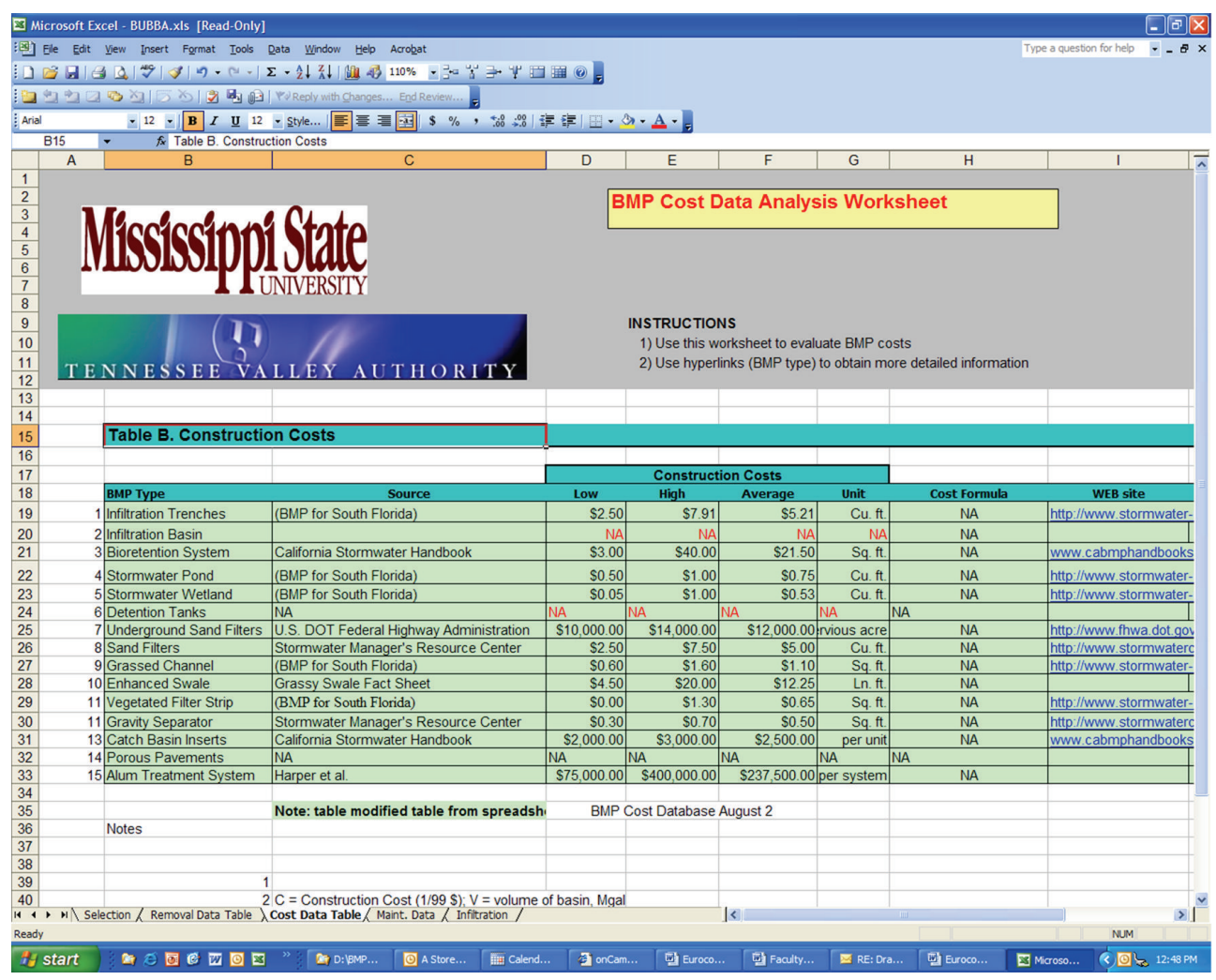

Figure 4: The Cost Data Table worksheet.

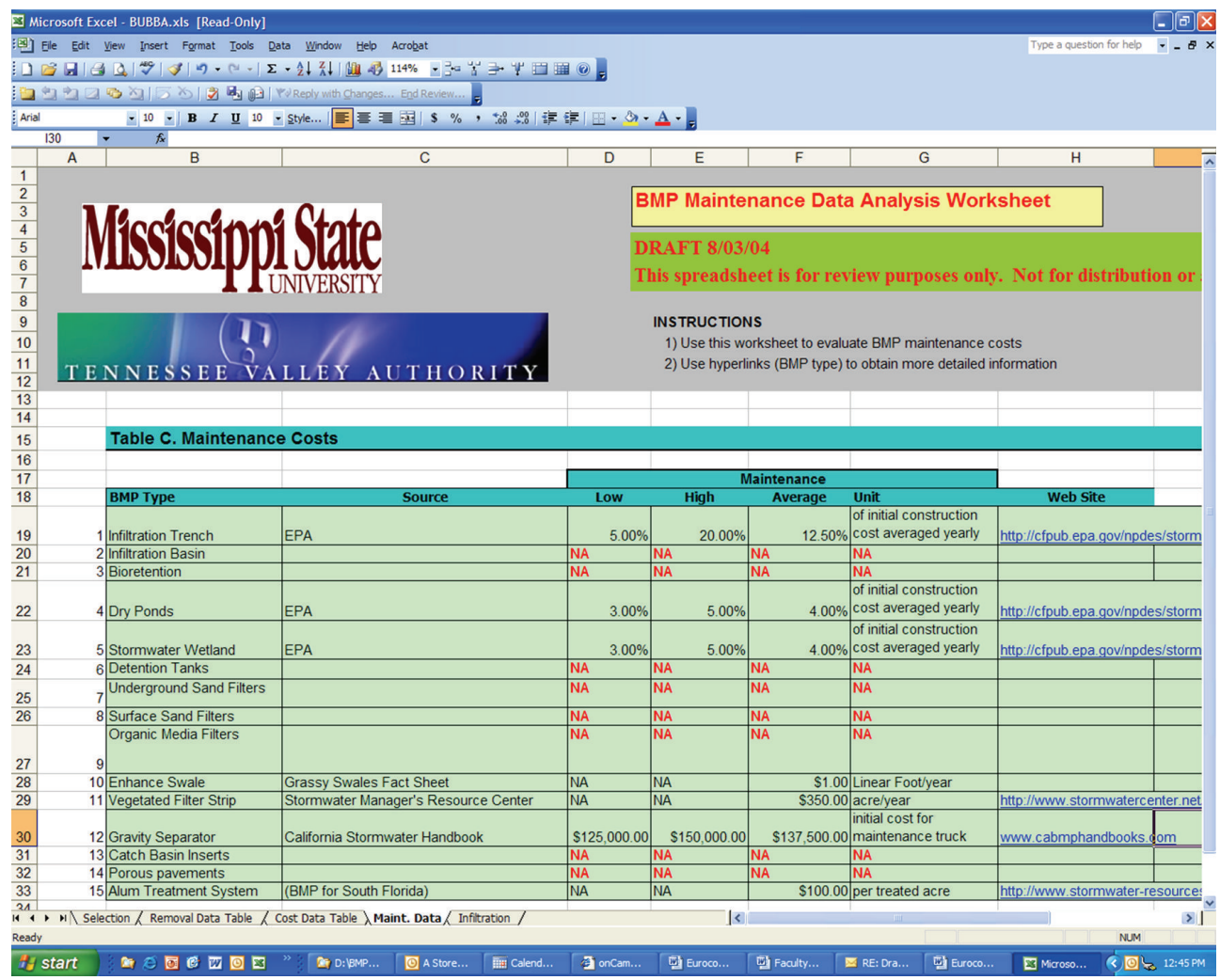

FIgUre 5: The Maintenance Data Table worksheet. 


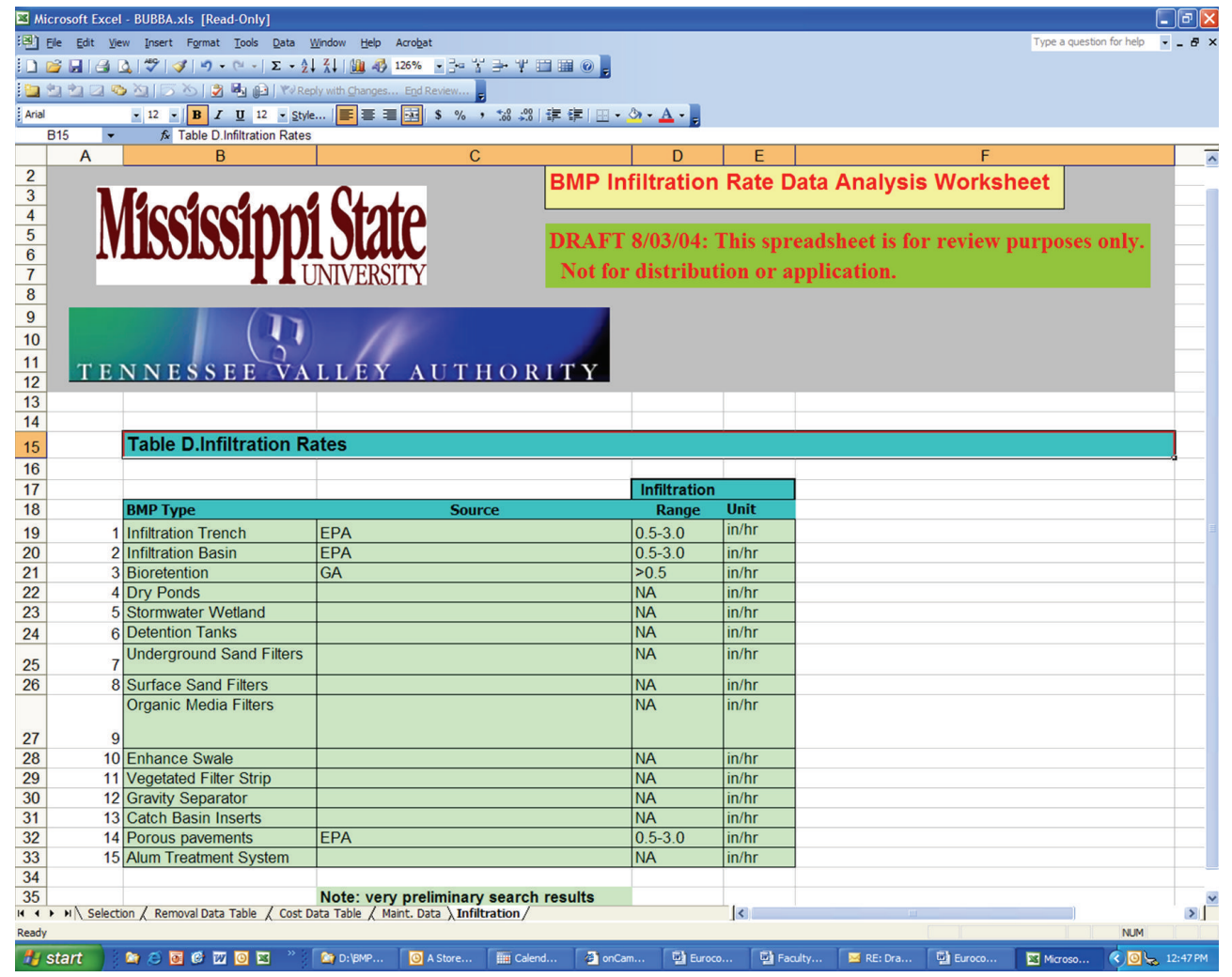

Figure 6: The Infiltration Data Table worksheet.

the Area Tools extension is launched, an additional column is added to the attribute table, which is in .DBF format, containing area values in various units. At this point the attribute table has an ID or name for each BMP plus an area calculation. The table is now ready for linking with the database containing BMP costs and characteristics.

The initial version of Latis used ESRI ArcView as the underlying spatial engine. Until recently, ArcView was the most common GIS/spatial interface available. It has been superseded by ArcGIS as the flagship desktop GIS package in the world. Unfortunately, both of these packages are relatively costly and require significant training. A traditional CAD package could also be used to create the point, line, or polygon file required to populate the land use and land cover screen. The CAD package with the largest market share is Autodesk AutoCAD. But like ArcGIS, it is expensive and requires quite a bit of training.

MapWindow, a free, open source desktop GIS, appears to be a more viable candidate to act as the spatial interface since it solves both the cost and source code problems. It is currently the underlying graphic package for BASINS 4.0. A more detailed description of the product may be found at http://www.mapwindow.org/.

Version 1.0 of the Latis graphical user interface was created by Dynamic Solutions, LLC, as a first step toward a general graphical user interface to create, edit, and display HSPF networks as used in these example site applications. The first version has limited capabilities but is designed for continued improvements as the system matures. Figure 7 shows a sample network with the segment edit popup menu displayed.

\section{Latis Testing and Review}

Initial testing of the system was designed to demonstrate applicability and identify needed improvements. Three sites were selected for testing-an existing industrial site, a proposed commercial site, and a proposed industrial megasite. Neither schedule nor funding allowed for validation of the results to field observations, so the results are considered useful mainly in a plan-to-plan comparison mode.

3.1. Eurocopter Test Site. The American Eurocopter site occupies $36 \mathrm{Ha}$ adjacent to the Golden Triangle Regional Airport in western Lowndes County, Mississippi. The Phase I development consists of a manufacturing building, taxiway, and loading dock plus adjacent roads, parking areas, walkways, and lawns. In Step 1 of the process, Phase I developments were delineated into subcatchment areas for calculating rainfall runoff as shown in Figure 8. ArcView was used to collect subwatershed land use information to be used in the HSPF model.

Postconstruction drawings were collected and used to generate area definitions. The original file structure was Autodesk AutoCAD provided by Neel-Schaffer Inc. These line drawings were imported into ArcView and converted to a shape file. The land use areas were defined as pervious and 


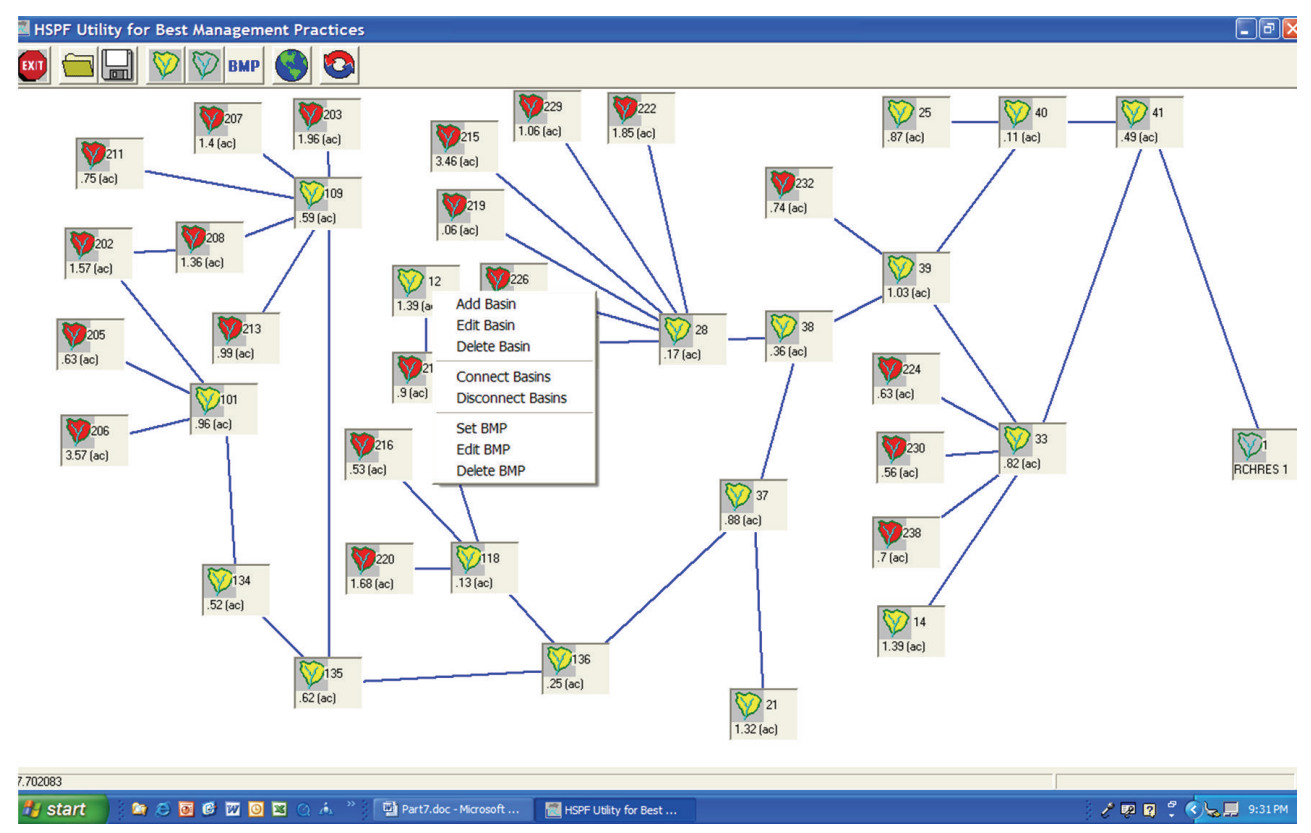

Figure 7: Simple HSPF Interface.

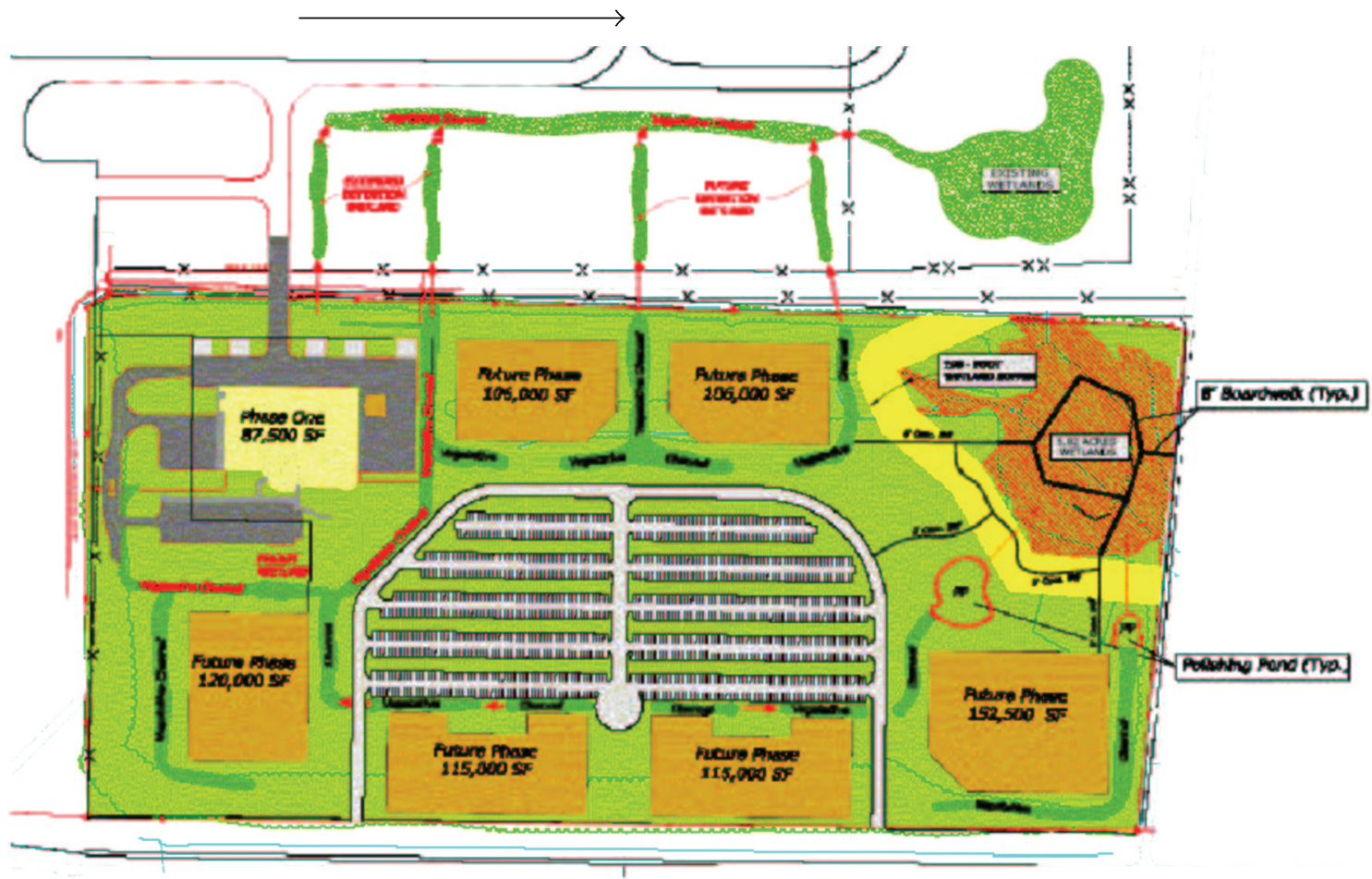

Figure 8: American Eurocopter site layout (Source: TVA).

impervious cover and broken into subwatersheds as required by HSPF. These values were compared to area values found in the original AutoCAD file to verify that spatial accuracy had not been lost during the translation.

Area Tools, an ArcView extension, was used to calculate area required for the HSPF model analysis. When the BMP theme is first created no area column exists. When the BMP theme is selected and the Area Tools extension is launched an additional column is added to the attribute table, which is in .DBF format, containing area values in various units. At this point the attribute table has an ID or name for each BMP plus an area calculation. The table is now ready for linking with the database containing BMP costs and characteristics. 


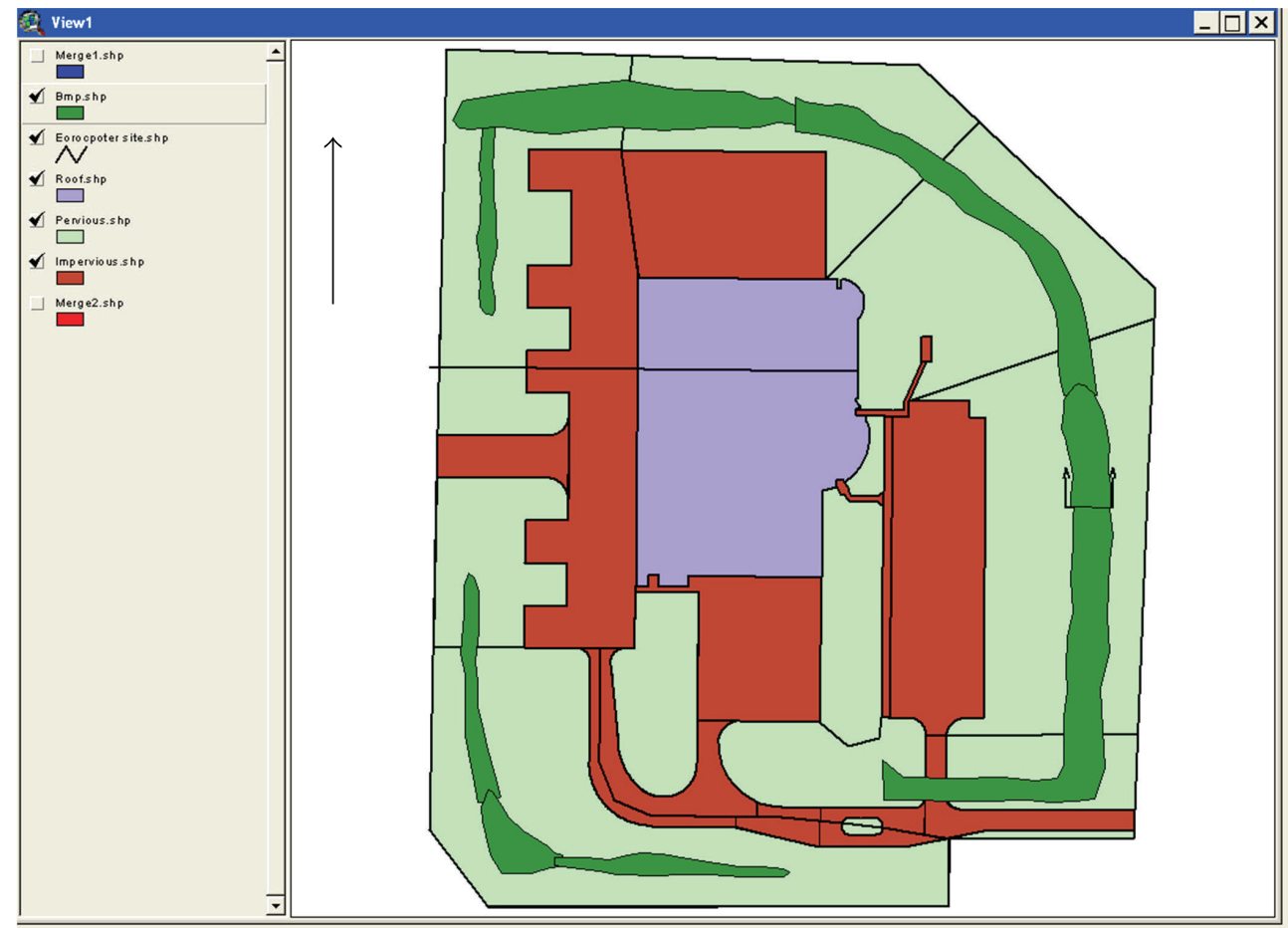

Figure 9: Eurocopter site in ArcView.

Four site configurations were tested with HSPF using meteorological conditions for the period March 1992 through June 1995:

(i) predevelopment,

(ii) as-built,

(iii) as-built with multiple BMP,

(iv) as-built with a single BMP in the outlet channel.

As-built conditions consisted of those shown in Figure 9. Predevelopment model conditions consisted of the schematization shown, but with all segments considered to be pervious vegetated land with low and high expected values of infiltration parameter $(0.025$ to $0.25 \mathrm{~cm} / \mathrm{hr})$, canopy storage $(0.25$ to $0.58 \mathrm{~cm})$, and soil storage $(0.75$ to $20 \mathrm{~cm})$ as described in the BMP spreadsheet. For the multiple BMP configuration, features consisting of bioretention swales with soil modification and check dams were incorporated, exercising the BMP selection spreadsheet described above to identify the infiltration rate of the augmented bioretention swales $(2.5 \mathrm{~cm} / \mathrm{hr})$. The slopes of the land segments were also reduced to $0.0001 \mathrm{~m} / \mathrm{m}$ to represent the slower runoff rate induced by check dams in the swales, but check dams were not explicitly modeled. The single BMP modeled in the last configuration consisted of a $1.2 \mathrm{~m}$ high check dam in the site outlet channel, containing a $1 \mathrm{~m}$ wide notch with a sill $0.2 \mathrm{~m}$ above the ground. A check dam of that size will impound up to about $850 \mathrm{~m}^{3}$ of water in the outlet channel. The notch was sized to contain the modeled event flow and limit peak flow to the maximum flow shown for the low estimate of predevelopment configuration runoff.

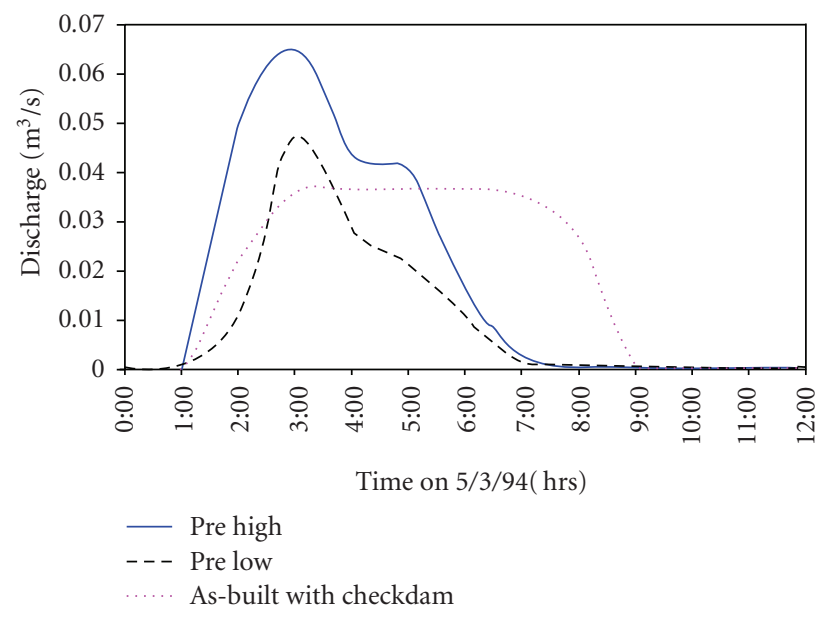

FIGURE 10: Comparison of HSPF model results for the Eurocopter predevelopment and as-built conditions with a check dam in the outlet channel.

Multiple BMPs were effective, reducing the peak discharge to a lower level $\left(0.035 \mathrm{~m}^{3} / \mathrm{sec}\right)$ than predevelopment conditions; however, they would be expensive. A calculation using the BMP Cost spreadsheet suggests that their cost could exceed $\$ 500,000$.

Figure 10 shows results for a single check dam compared with predevelopment conditions. The peak discharge was significantly reduced, from the high estimate (low infiltration) of $0.071 \mathrm{~m}^{3} / \mathrm{sec}$ to about $0.035 \mathrm{~m}^{3} / \mathrm{sec}$, the same as the multiple BMP solution and lower than the predevelopment 


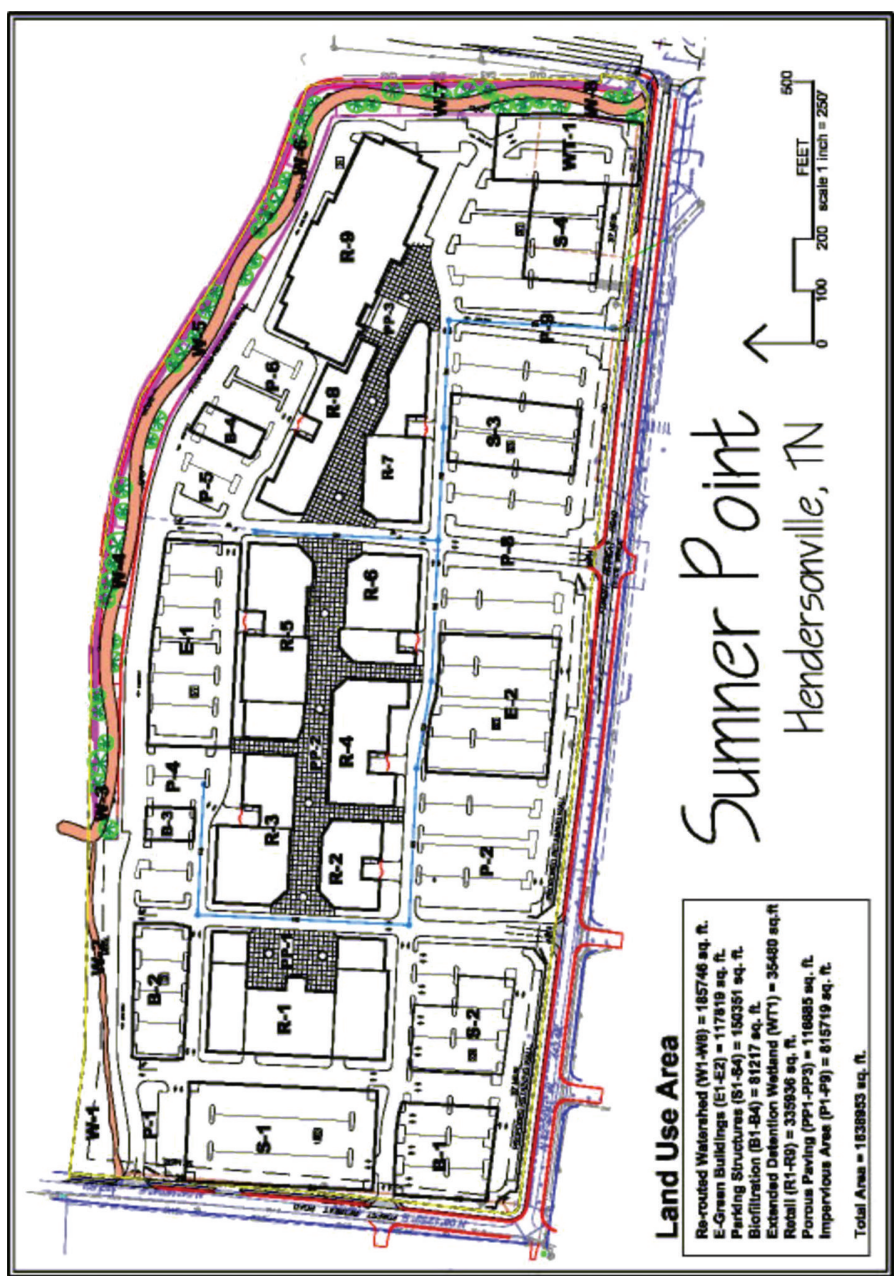

Figure 11: Sumner Point Site Plan (Source: TVA).

low flow (high infiltration) estimate of $0.048 \mathrm{~m}^{3} / \mathrm{sec}$. The duration of flow was about 2 hours longer $(8$ hours versus 6 for the predevelopment hydrograph) and total volume was not reduced, since the computed soil infiltration was not increased in the channel even though that will certainly occur. Water retained beneath the sill in the check dam notch will evaporate and infiltrate into the soil. Thus the check dam is shown to be an effective solution in terms of both total runoff and peak discharge being no greater than under predevelopment conditions. The BMP database indicates that a wet basin of the needed size will cost $\$ 15,000$ to $\$ 30,000$ to build from scratch, less expensive than the multiple BMP cost of $\$ 500,000$; however, since the channel is already there, it would cost only $\$ 5,000$ to $\$ 10,000$ to build the specified check dam with an earth core and riprap covering. This latter cost is well within the range of acceptable implementation costs.

Larger rainfall events will require more flow detention capacity than the typical rainfall modeled here and a single large detention pond is not an ideal solution; but the results suggest that the goal of returning to predevelopment hydrology can be achieved in a cost-effective way with well- designed BMP. A validated hydrological model should be used to confirm that finding and design the BMP details.

3.2. Sumner Point Test Site. A second test examined some BMP/LID features at a proposed commercial development in Hendersonville, Tennessee. The purpose of this application was to quantify the contribution of several BMP/LID features to reduce the as-built runoff rate to at or below the predevelopment level. A preliminary version of the proposed development is shown in Figure 11. It consists of a $16 \mathrm{Ha}$ site with a $16 \mathrm{~m}$ natural elevation change [19] converted by cut-and-fill to a low slope development with shopping, convention/hotel, and residential facilities.

The initial site drawings, in AutoCAD format, were provided by Raven Engineering, LLC of Nashville, TN. The site plan was then converted to ArcGIS for additional spatial analysis. BMP/LID features were selected by TVA and added to the original site plan. Characteristics of those features were obtained from the BMP selection spreadsheet. Area values for each BMP/LID feature were then generated for inclusion in the model. Rainfall-runoff for the site 


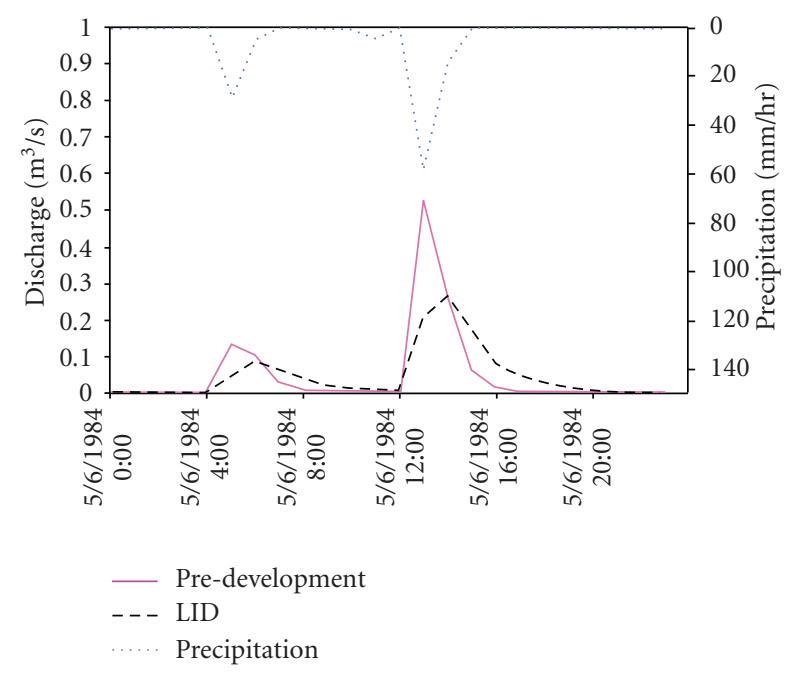

Figure 12: Sumner Point Precipitation and modeled Total Surface Runoff on 6 May 1984.

was modeled using HSPF. The AutoCAD drawing of the development was used to construct a drainage network to be coded in HSPF. At the property boundary, the land segments drain into a single channel reach in the model. The various areas shown in Figure 11-retail, parking, stream, and so forth-were assigned codes to represent the type of space to be used by HSPF. The model was run using either default coefficient values or, in the case of the low-impact development features, values in the BMP spreadsheet. No validation was attempted. For these reasons, these results should be viewed as preliminary and indicative of what might occur under similar conditions and not as absolute predictions.

Two site conditions were tested: predevelopment and proposed development with BMP/LID. Rainfall runoff was simulated for the period 1980 through 1989, using meteorological data from the Nashville, TN airport as downloaded from EPA's BASINS website [4] and extracted using the BASINS software.

Several types of BMP/LID features were modeled by treating them as land features (PERLND in HSPF terminology) with appropriate infiltration coefficients and, in some cases, outflow constrained by standard hydraulic equations for a broad crested weir. That has the effect of retaining the first flush of runoff and then slowly letting it drain into the next segment. The LID features for biofiltration units (rain gardens) were thus modeled to retain inflowing water until a water depth of $0.3 \mathrm{~m}$ accumulated, and then the flow drained out as if passing over a weir. For a proposed wetland in the southeast corner of the site, a depth of $1 \mathrm{~m}$ was used as the accumulation water level. All other areas drained at a rate corresponding to their slope, size, and degree of pervious infiltration. Infiltration coefficients were selected from the BMP spreadsheet.

Since model schematization can affect computed results, the same schematic was used for both the predevelopment and developed site configuration, changing the surface slopes, infiltration coefficients (default values for the predevelopment condition), and water accumulation to approximate the actual site conditions.

Results for the tested conditions under one rainfall event (in which $100 \mathrm{~mm}$ of rain fell on 6 May 1984) are shown in Figure 12. As can be seen, the low-impact site development plan produced a peak total surface runoff at the site boundary of $0.3 \mathrm{~m}^{3} / \mathrm{sec}$, compared with $0.5 \mathrm{~m}^{3} / \mathrm{sec}$ under the predevelopment condition, and the peak flow was delayed by about an hour. Thus, the BMP plan can be seen to be highly effective, not only preventing any adverse impact on downstream flow, but actually reducing both total runoff and peak flow magnitude from the predevelopment state. In this case the BMP might be considered excessive if the goal was only to maintain the runoff status quo and the system redesigned to provide less hydrologic retention; however, if developers wanted to demonstrate environmental excellence or mitigate for other impacts, such as increased nearby development, they can choose to implement the tested plan.

3.3. Tunica County Test Site. Latis was applied to a proposed industrial site in Tunica County in northeast Mississippi as shown in Figure 13. The gently sloping $900 \mathrm{Ha}$ site is located northeast of Tunica, MS, adjacent to U.S. Highway 61. Its current land use would be classified as agricultural. It is drained by three intermittent flow ditches that flow into Herron Bayou, which flows through the middle of the site. The site topography was modeled using high resolution LIDAR data collected by the U.S. Army Corps of Engineers, which were converted to elevations. These were used to define slopes and determine the location of streams and low points, which helped to establish the land segment boundaries suitable for drainage analyses. Soils data from the BASINS database were used to characterize the infiltration characteristics of the site. A site visit was used to characterize the existing vegetative cover. Rainfall data were generated for the site using meteorological data from Arkabutla Dam in Tate County, downloaded from EPA's BASINS website and extracted using the BASINS software.

The LIDAR data along with the region quad map were used to determine natural drainage patterns. These patterns were then used to separate the site into land segments which drain into a central reach, Herron Bayou. The various areas-impervious and pervious - were assigned coded numbers which HSPF uses to identify each land segment. Areas for each land segment were calculated for inclusion in the model.

Rainfall runoff for the site was modeled using HSPF. BMP/LID features were selected to best complement the site according to soil characteristics and land slope. Characteristics of those features were obtained from the BMP selection spreadsheet and standard hydraulic equations. Rainfall runoff was simulated for the period 1978 through 1980. Multiple site segmentations were tested with only fourteen segment results presented. 


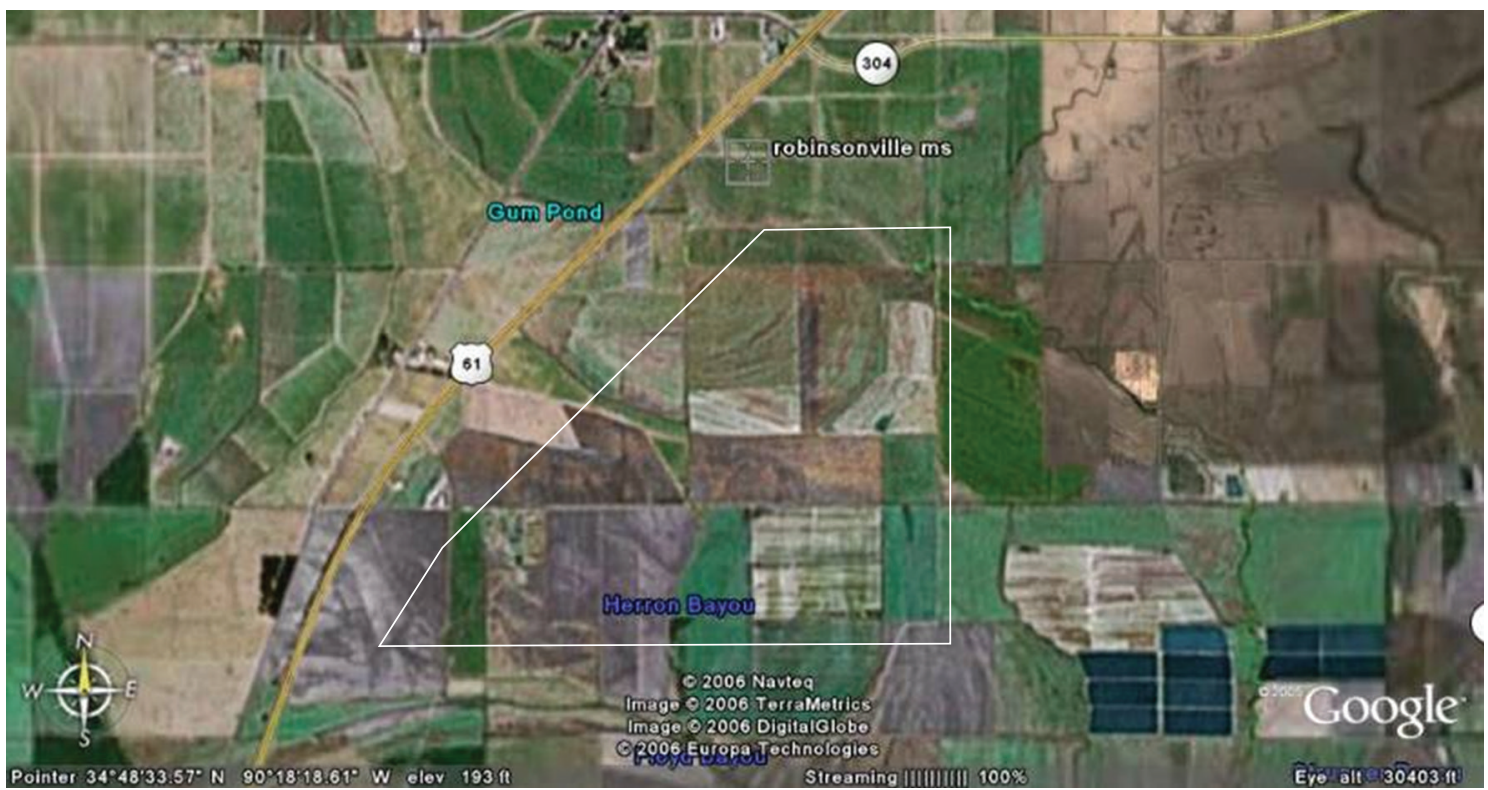

FIgURE 13: Location of Industrial Site (outlined in white) in Tunica County. (Adapted from Google Earth.)

For the final scenarios, four site conditions were tested:

(i) present agricultural use,

(ii) postdevelopment,

(iii) postdevelopment with BMP/LID,

(iv) worst-case condition.

The present use condition modeled all segments as pervious land segments. The postdevelopment included seven pervious land segments (PERLNDs) and seven impervious land segments (IMPLNDs). The worst-case condition modeled all segments as impervious land segments (IMPLNDs) to demonstrate what would happen if the entire site was covered with pavement. While this is an extreme, impractical case, it is useful to illustrate the upper limit on runoff from a given rainfall event.

The postdevelopment with BMP was modeled the same as postdevelopment without BMP except that the impervious land segments were subdivided in order to implement BMP. Two types of low-impact development features were tested. The pervious concrete BMP/LID feature was modeled by treating it as a pervious land segment with appropriate infiltration coefficients and storage capacity. The check dam BMP features were applied to the reach segments except Herron Bayou. The outflow from these segments was constrained by standard hydraulic equations for a broad crested weir. This has the effect of retaining the first flush of runoff and then slowly letting it drain into Herron Bayou. The BMP feature for check dams was first implemented using a maximum water depth of $0.3 \mathrm{~m}$. However, the magnitude of the site required much larger capacity in order to reduce the postdevelopment site runoff to predevelopment conditions. In order to achieve these results, the BMP modeled as check dams had to be raised to a height of $1.5 \mathrm{~m}$. This is an unusually high check dam and essentially suggests that a

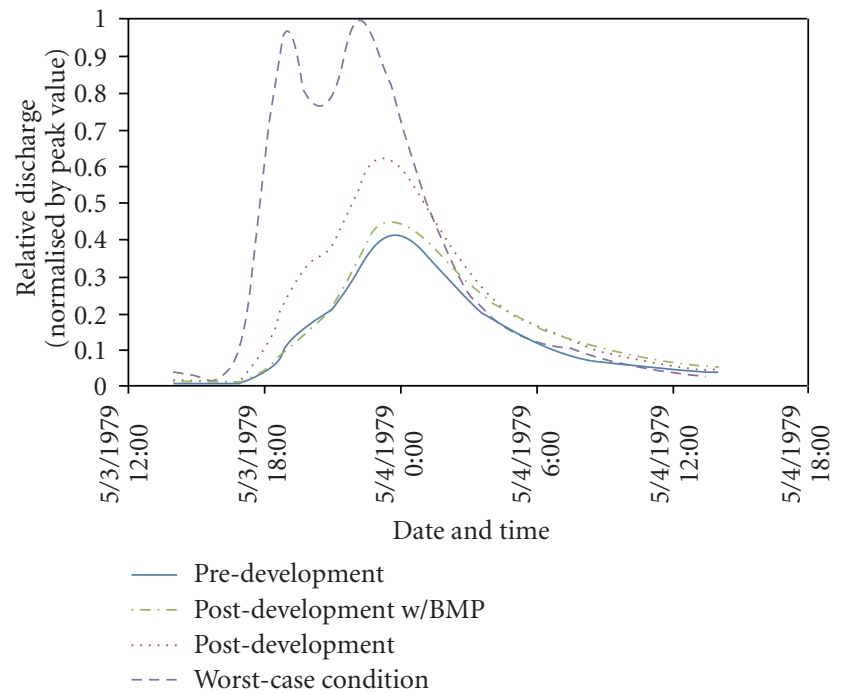

Figure 14: Tunica County Site modeled reach flow for all site conditions.

pond would be required to retain the optimum amount of water. All other areas drained at a rate corresponding to their slope, size, and degree of pervious infiltration.

Results for the tested conditions under one typical rainfall event (in which $130 \mathrm{~mm}$ of rain fell over a 24-hour period from 3 May to 4 May 1979) are shown in Figure 14, with the discharge from the site expressed in nondimensional form. The nondimensional presentation (normalized by dividing computed discharge by the peak discharge computed for the worst case (100\% paving) scenario) is used to emphasize that the model has not been validated by comparison with field observations of flow. Results from models that have not been validated are best used to indicate relative change, that is, 
to compare one scenario to another. The site development plan with selected BMP produced a peak total surface runoff at the site boundary of 0.44 , much below the 0.62 for the postdevelopment without BMP and only slightly above the 0.41 value for the present use condition.

Adding impervious surface to a site usually increases both the speed and amount of runoff. Figure 14 shows this effect clearly as the Worst Case scenario produces more than twice the peak discharge of the Present agriculture condition. The first peak is almost as large as the second for the Worst Case; whereas for Present use, the first peak is greatly attenuated by vegetative trapping and infiltration. The Post-development case, while generating only about a 50-percent increase in peak flow, could double the erosive power of Herron Bayou for the reasons described in the preceding section.

Figure 14 also shows that the total volume of runoff, indicated by the area under the curve, will be increased in the Post-development case; however, adding the selected BMP of check dams and porous pavement reduces both the peak flow and total volume to about the same as the Present agriculture case. Thus relatively simple low-impact design features offer the potential to maintain or even improve downstream water quality.

Costs of check dams, from a few hundred to a few thousand dollars each, can be insignificant when compared with other site development costs. Pond construction costs are higher, usually requiring at least some excavation and an engineered dam and spillway. For a dry pond capturing $200,000 \mathrm{~m}^{3}$ as needed for the tested condition, the BMP selection spreadsheet shows about $\$ 5$ millions to construct. The spreadsheet indicates an annual maintenance cost of about $\$ 0.04$ per dollar of construction cost or $\$ 200,000$, much of which goes toward removing sediment deposits behind the dam, which can be minimized by other BMP, such as lawns and grassy swales.

3.4. Peer Review. Once the initial tests were completed, a peer review of the model was held at the Thad Cochran Research, Technology, and Economic Development Park on the campus of Mississippi State University. Twelve individuals attended. Six were Mississippi State researchers, two were from private engineering firms, two were from nongovernmental organizations (NGOs), and two were from state regulatory agencies.

The results of the peer review feedback and the prioritization improvements, in ranked order, included:

(1) make the product more user-friendly/integrate the information/product;

(2) show the benefits/make the benefits more explicitgive incentive to use the program. Illustrate how it supports meeting permitting requirements;

(3) validate the Model;

(4) define Target Market (who)—regional? beyond?

(5) standardize Costs-(National Standard Database), include traditional design cost estimates;
(6) improve estimates of BMP removals/efficiencies as related to construction;

(7) make comparisons (cost/benefits) easy;

(8) integrate with CAD and/or GIS;

(9) relate to CWP regulations or recommendations;

(10) post audit studies;

(11) add effects of upstream runoff to model;

(12) tie into Green Design.

\section{Second Generation Latis}

4.1. Survey of Needs. As noted by Singh [1], the future of hydrologic modeling will demand a transformation to userfriendly forms and require the possession of minimal technical expertise by the end-user. This position is supported by feedback from the peer review described above, a well as the results of a survey conducted in 2008. In order to assess the perceptions of LID/BMP techniques in the Southeast, a webbased questionnaire was designed and distributed to design professionals throughout the southern portions of Alabama, Louisiana, and Mississippi. These areas were targeted as part of ongoing research with the Northern Gulf Institute (NGI) which was created in 2006 to support research relevant to the Northern Gulf of Mexico. The target audience for the survey was design and planning professionals including civil/environmental engineers, landscape architects, and related professions.

The survey, Best Management Practices in the Development Industry, was formatted into a series of 28 questions designed to be taken in 10-15 minutes. Topics of investigation included demographics, firm and project information, familiarity with LID/BMP, client perception, marketability, cost feasibility, availability of hydrologic modeling tools, technological needs, and interface preferences. An e-mail database of respondents was generated using internet resources, departmental contacts, organizational contacts, and publicly available information. The survey was distributed twice via an e-mail link to approximately 1,200 respondents. The total number of recipients is strictly an estimate because many individuals agreed to distribute the study to other practicing professionals. The survey received a total of 141 responses over a one-month time period. This response count exceeded the arbitrary goal of 100 .

Distribution to the target audience was a success. Nearly $80 \%$ of the survey population consisted of civil/environmental engineers and landscape architects practicing in various areas throughout Alabama, Louisiana, and Mississippi. While over $60 \%$ of the respondents said they were very comfortable with Excel, only $11 \%$ indicated they were very comfortable with ArcView or ArcGIS. Only $1 \%$ felt very comfortable with HSPF. When asked if "an all-inclusive, user-friendly model was available for assessing site plans", almost $70 \%$ said they would use such a tool if one existed. Fifty percent said they would be willing to pay up to $\$ 1,000$ for such a product. $56 \%$ indicated that they would prefer a spreadsheet linked to a CAD system such as AutoCAD or MicroStation. 


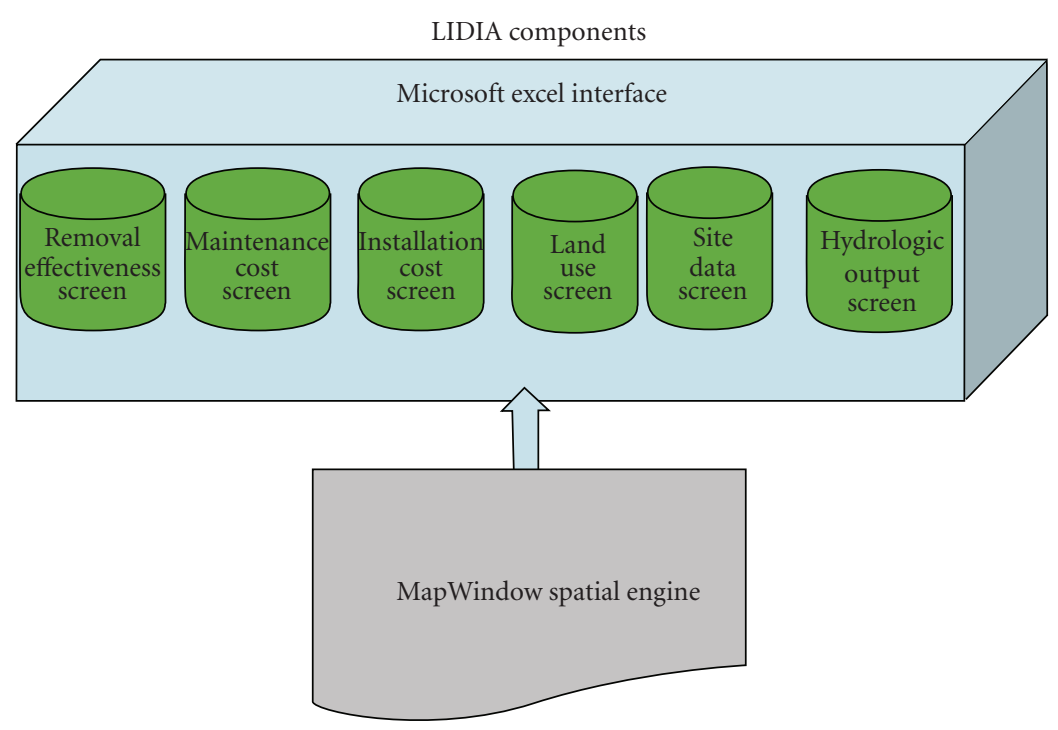

FIGURE 15: Low-Impact Development Implementation Assessment.

The use of an online survey in assessing the design industry's perceived lack of adoption of LID/BMP techniques proved successful. Satisfying governmental requirements proved to be the primary driving force in implementing these strategies. Three leading factors-cost, client opposition, and traditional methodologies-have hindered many designers from integrating LID/BMP techniques into site plans. Each of these factors could potentially be mitigated through the development of a comprehensive, userfriendly site planning tool. An Excel spreadsheet interface may be a valid candidate considering its wide-acceptance, capabilities, and ease of use. An anonymous respondent commented that "the cost comparison of BMP/LID to traditional development strategies would be most valuable for convincing clients to implement strategies where regulations do not require them." However, until sustainable storm water measures are mandated on all levels of government, many designers will most likely continue to utilize traditional storm water management techniques.

4.2. LIDIA Tool. Sufficient evidence from the Best Management Practices in the Development Industry survey indicated that the development of a site assessment tool would be well received by the design and development industries. This new tool would build on the basic framework of the original Latis. It would enable the user to analyze a site's hydrologic output when incorporating various BMP solutions. The three primary BMP sheets from Latisremoval effectiveness, maintenance cost, and installation cost-would be included. The system would also include a spatial engine that is available in the public domain. The second generation of Latis has been named Latis-LIDIA- the Low-Impact Development Implementation Assessment tool; see Figure 15.
TABLE 1: Latis versus Latis-LIDIA.

\begin{tabular}{lll}
\hline Component & Latis & Latis-LIDIA \\
\hline (1) Interface & $\begin{array}{l}\text { HSPF and } \\
\text { Spreadsheet }\end{array}$ & Spreadsheet \\
\hline (2) Hydrologic Simulation & HSPF & $\begin{array}{l}\text { Spreadsheet, } \\
\text { via SCS-CN } \\
\text { Method }\end{array}$ \\
\hline (3) Model Type & Continuous & Single-event \\
\hline (4) Water Quality-Pollutants & HSPF & Not Available \\
\hline (5) Spatial Calculations & $\begin{array}{l}\text { ArcGIS, } \\
\text { AutoCad, or }\end{array}$ & MapWindow \\
\hline (6) BMP/LID Effectiveness & Spreadsheet & Spreadsheet \\
\hline (7) BMP/LID Costing & Spreadsheet & Spreadsheet \\
\hline (8) Availability & Public Domain & $\begin{array}{l}\text { Public } \\
\text { Domain }\end{array}$ \\
\hline
\end{tabular}

A Microsoft Excel spreadsheet interface was selected for the initial attempt in developing the model. Microsoft Excel is a powerful, user-friendly tool that is widely accepted throughout the profession and supports both the familiar workbook environment and Visual Basic for Application (VBA) macro programming. Like Latis, LIDIA is founded on the underlying concept of simulating the effectiveness and cost of implementing LID/BMP techniques. Latis-LIDIA is expected to function as a stand-alone tool instead of requiring specialized training in HSPF and similar external applications. The similarities and differences between Latis and Latis-LIDIA are summarized in Table 1.

In its current phase, LIDIA is capable of estimating runoff based on pre- and postdeveloped site conditions using 


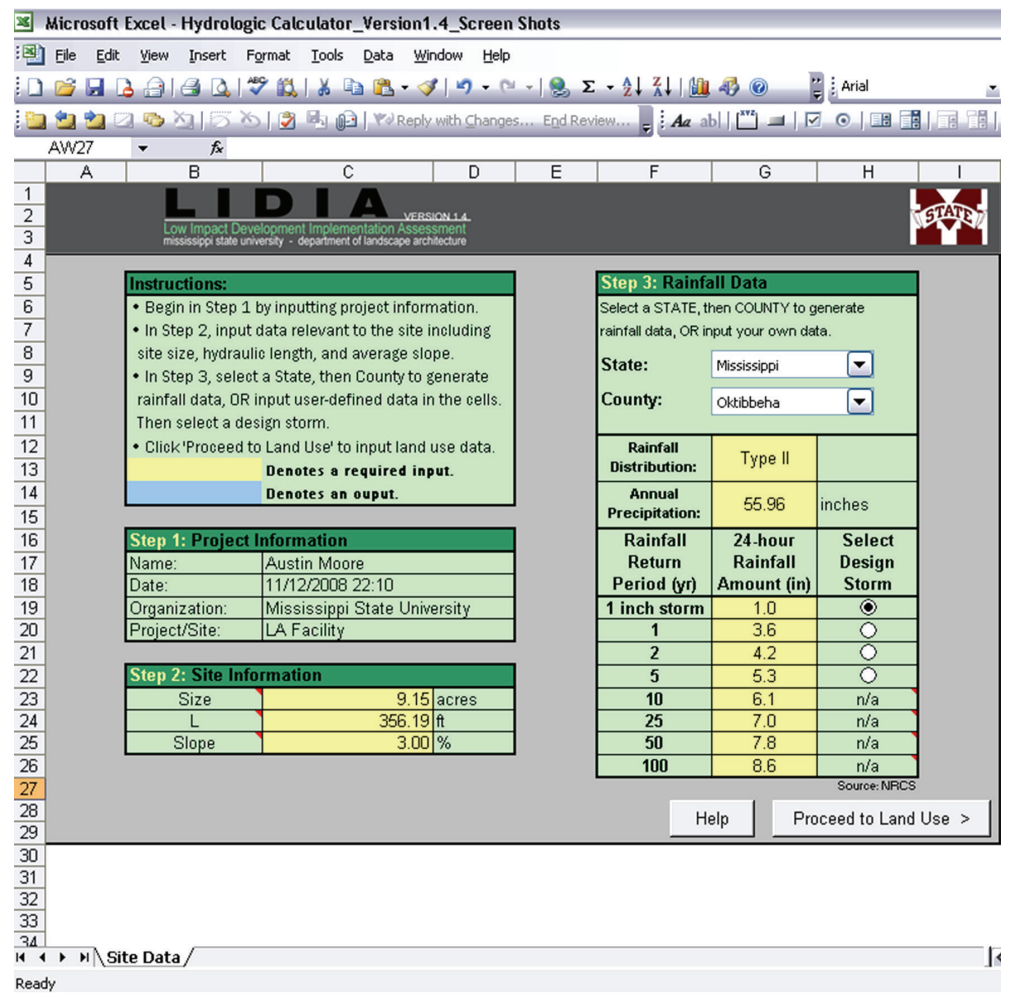

Figure 16: Latis-LIDIA Site Data Input Screen.

the widely-accepted Soil Conservation Science (SCS) runoff curve number $(\mathrm{CN})$ method. The first step in the model requires user input of project information, site dimensions, and precipitation data (Figure 16). Precipitation data are model-generated by selection of state and county, or the data can be manually entered by user-defined values. The precipitation database is tailored for sites within Alabama, Louisiana, and Mississippi.

Upon completion of site-specific information and selection of a design storm, the user must characterize the site based on its land use and land cover for each respective hydrologic soil group (HSG), cover type, and size (Figure 17).

After characterizing the site, a runoff $\mathrm{CN}$ is generated and printable results are displayed. Currently, model outputs include predeveloped versus postdeveloped conditions; storm event peak flow, runoff, and hydrographs; and annual runoff volumes (Figure 18). Future development of the model is expected to include pollutant loading computations, a database selection of BMP, and a cost component. Together, these components will assist planners and designers in not only calculating, but also communicating the effectiveness that LID/BMP strategies have on reducing water quantity and improving water quality in planning and designing sustainable landscapes.

4.3. BMP Database Update. Since the completion of the Latis development project final report in 2005 and the startup of this effort, some changes have been made to the three data sources listed previously. Research on the status of these three databases indicates that the Georgia Stormwater Manual only added one BMP type, that being a stormwater pond. The Federal Highway Administration has apparently remained constant. The EPA BMP database has had the most extensive modifications and now includes the following categories and information packets called factsheets that were not included in the Latis study. The 2007 updated version of the BMP spreadsheet, which may be found at http://www2.msstate.edu/ gww/MSU_BMP_Database_2007.xls, now contains the following additions.

(i) Planning

(a) Development-6 BMP,

(b) Preservation-6 BMP (including riparian buffers).

(ii) Controls
(a) Erosion-14 BMP,
(b) Runoff-4 BMP,
(c) Sediment-13 BMP.

(iii) Management
(a) Filtration-8 BMP,
(b) Infiltration-5 BMP,
(c) Retention_Detention-5 BMP,
(d) Streets-4 BMP. 


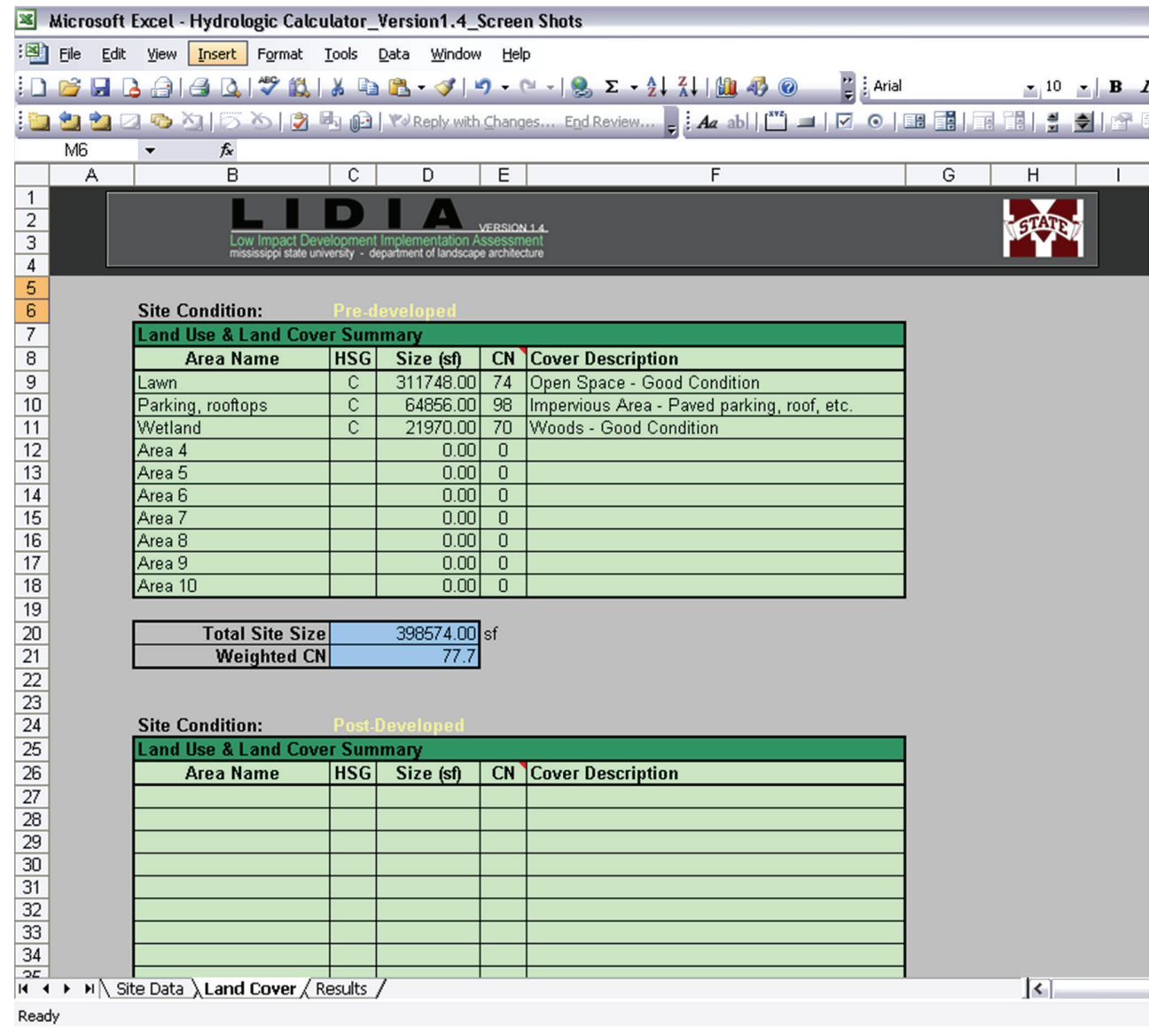

Figure 17: Latis-LIDIA Land Use and Land Cover Input Screen.

\section{Conclusions}

Initial development and testing of the Latis DSS has shown that the original objectives can be met to produce a public domain tool that will support BMP/LID decision-making in a form that is practical and useful for consulting firms and small government offices. This is a significant innovation in that heretofore only modelers with sophisticated computer skills could conduct such studies.

Further work, including results from the peer review, the on-line survey, and numerous conference presentations indicate a growing demand for an all-inclusive, user-friendly model capable of calculating pre- and postdevelopment runoffs, calculating pollutant loading rates, proposing BMP/LID storm water solutions, and computing cost components associated with implementing such strategies. This demand is driven on the one side by the growing public awareness of water quality issues and the resulting expansion of local, state, and federal regulations. Private sector design professionals see a growing market for providing these services, while at the same time often lacking the technical expertise to utilize existing technologies. The challenge will be to ensure that models such as the one currently under development will provide the simplified interface requested by the users, while at the same time maintaining sound science and engineering.
Two versions of the Latis DSS are presently available to meet the challenges-basic Latis requires knowledge of, and skill in using, the hydrologic model HSPF or a similar model, including nonstandard use of the HSPF model. LatisLIDIA offers a simpler approach, making it available to a wider range of users, but with the limitation of event-based hydrology (i.e., flow duration analyses are not possible) and no capability to explicitly consider water quality performance of BMP/LID.

The potential for matching such supply and demand is quite promising. Hardware cost and availability are no longer issues for running such models. Software costs have not matched the decline seen in hardware, but the number of packages has certainly increased. Probably more importantly, college students are being exposed to a wider range of programs and models than previous generations of engineers, architects, and landscape architects. This generation will probably see a rapid expansion in both the quality and quantity of tools capable of assisting in the implementation of storm water solutions. The next frontier will be webbased solutions. Currently, the technology is in place to easily collect, store, and share required data inputs such as soil type, rainfall, and topography. The next step will be to enable distributive processing capabilities for the models. The third component in this process is the human element. Significant outreach efforts will be required to educate practicing design 


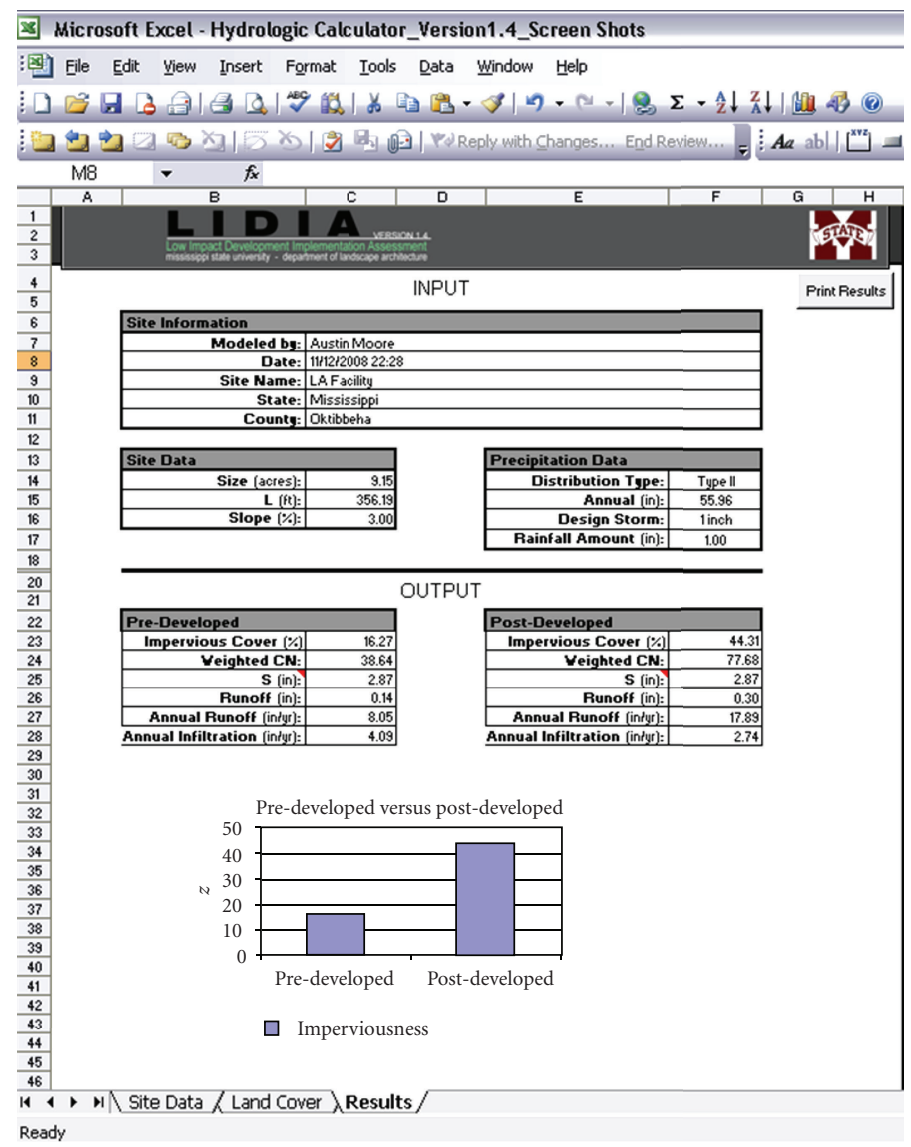

Figure 18: Latis-LIDIA Model Output Screen.

professionals. Workshops, conferences, and continuing education clinics will be needed if the marketplace is to keep up with advances in theory and technology.

\section{Acknowledgment}

The work described here was supported by the Mississippi Department of Environmental Quality, U.S. Environmental Protection Agency, Tennessee Valley Authority, Yazoo River Delta Joint Water Management District, Northern Gulf Institute, and Mississippi State University.

\section{References}

[1] United States Department of Agriculture, Urban hydrology for small watersheds. Technical Release 55 (TR-55), Natural Resources Conservation Service, Conservation Engineering Division, Washington, DC, USA, 2nd edition, 1986.

[2] U.S. Army Engineer Research and Development Center, "GSSHA-Gridded Surface Subsurface Hydrologic Analysis, Vicksburg MS," January 2010, http://chl.erdc.usace.army .mil/gssha.

[3] V. P. Singh and D. A. Woolhiser, "Mathematical modeling of watershed hydrology," Journal of Hydrologic Engineering, vol. 7, no. 4, pp. 270-292, 2002.

[4] U.S. Environmental Protection Agency (USEPA), "Better Assessment Science Integrating Point and Nonpoint Sources
(BASINS)," January 2010, http://www.epa.gov/waterscience/ basins/.

[5] V. P. Singh, Ed., Computer Models of Watershed Hydrology, Water Resources, Littleton, Colo, USA, 1995.

[6] V. P. Singh and D. K. Frevert, Eds., Mathematical Models of Large Watershed Hydrology, Water Resources, Littleton, Colo, USA, 2002.

[7] "Database of Hydrologic Models," Texas A\&M University, February 2009, http://hydrologicmodels.tamu.edu/.

[8] B. R. Bicknell, J. C. Imhoff, J. L. Kittle Jr., T. H. Jobes, and A. S. Donigian Jr., Hydrological Simulation Program-Fortran: HSPF, Version 12 User's Manual. National Exposure Research Laboratory, U.S. Environmental Protection Agency, Athens, Ga, USA, 2001.

[9] A. S. Donigian, B. R. Bicknell, and J. C. Imhoff, "Chapter 12: Hydrological Simulation Program-FORTRAN (HSPF)," in Computer Models of Watershed Hydrology, V. P. Sigh, Ed., pp. 395-442, Water Resources, Littleton, Colo, USA, 1995.

[10] J. N. Diaz-Ramirez, Modeling sediment export potential of the Rio Caonillas watershed, M.S. thesis, University of Puerto Rico, Mayaguez, Puerto Rico, USA, 2004.

[11] J. N. Diaz-Ramirez, Assessment of uncertainty in flow model parameters, channel hydraulic properties, and rainfall data of a Lumped watershed model, Ph.D. dissertation, Mississippi State University, Starkville, Miss, USA, 2007.

[12] ISBMPD, "International Stormwater Best Management Practices Database," December 2008, http://www.bmpdatabase .org/. 
[13] FHWA, "Stormwater Best Management Practices in an UltraUrban Setting: Selection and Monitoring," U.S. Department of Transportation, Federal Highway Administration, December 2008, http://www.fhwa.dot.gov/environment/ultraurb/.

[14] U.S. Environmental Protection Agency (USEPA), "National Pollution Discharge Elimination System, Post-Construction Storm Water Management in New Development \& Redevelopment, BMP Fact Sheets," U.S. Environmental Protection Agency, December 2008, http://cfpub.epa.gov/npdes/ stormwater/menuofBMP/post.cfm.

[15] Atlanta Regional Commission, "Georgia Stormwater Management Manual, Volume 2: Technical Handbook," December 2008, http://www.georgiastormwater.com/.

[16] South Florida Water Management District, "Best Management Practices for South Florida Urban Stormwater Management Systems," June 2009, http://www.sfwmd.gov/.

[17] U.S. Supreme Court, "Daubert v. Merrell Dow Pharmaceuticals, 509 U.S. 579,” February 2009, http://supreme.justia .com/us/509/579/case.html.

[18] ESRI, "Knowledge Base," February 2009, http://support .esri.com/index.cfm?fa=knowledgeBase.gateway.

[19] Beaver Engineering, "Preliminary Geotechnical Engineering Report," Sumner Point, Beaver Engineering, Inc., Nashville, Tenn, August 2004. 

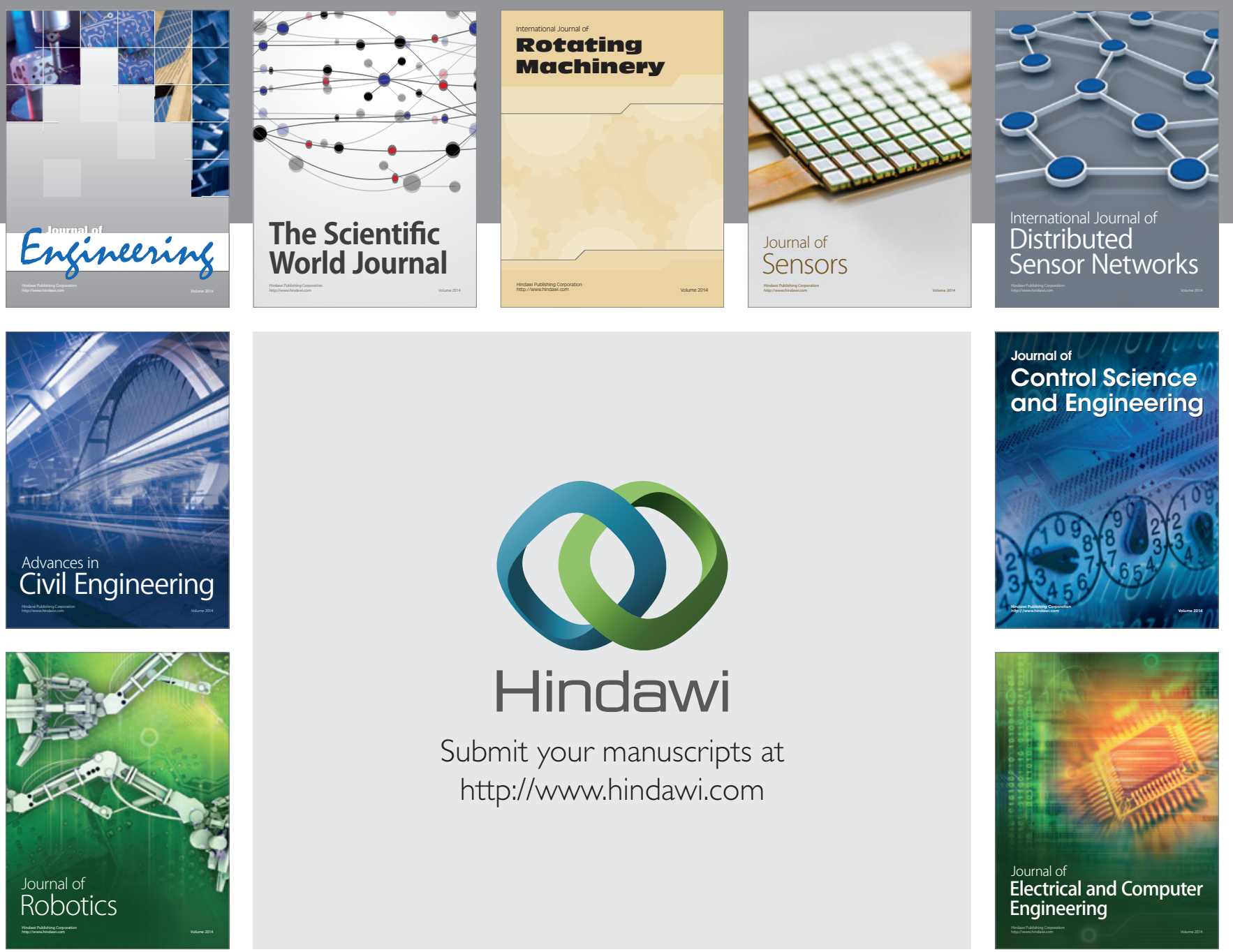

Submit your manuscripts at

http://www.hindawi.com
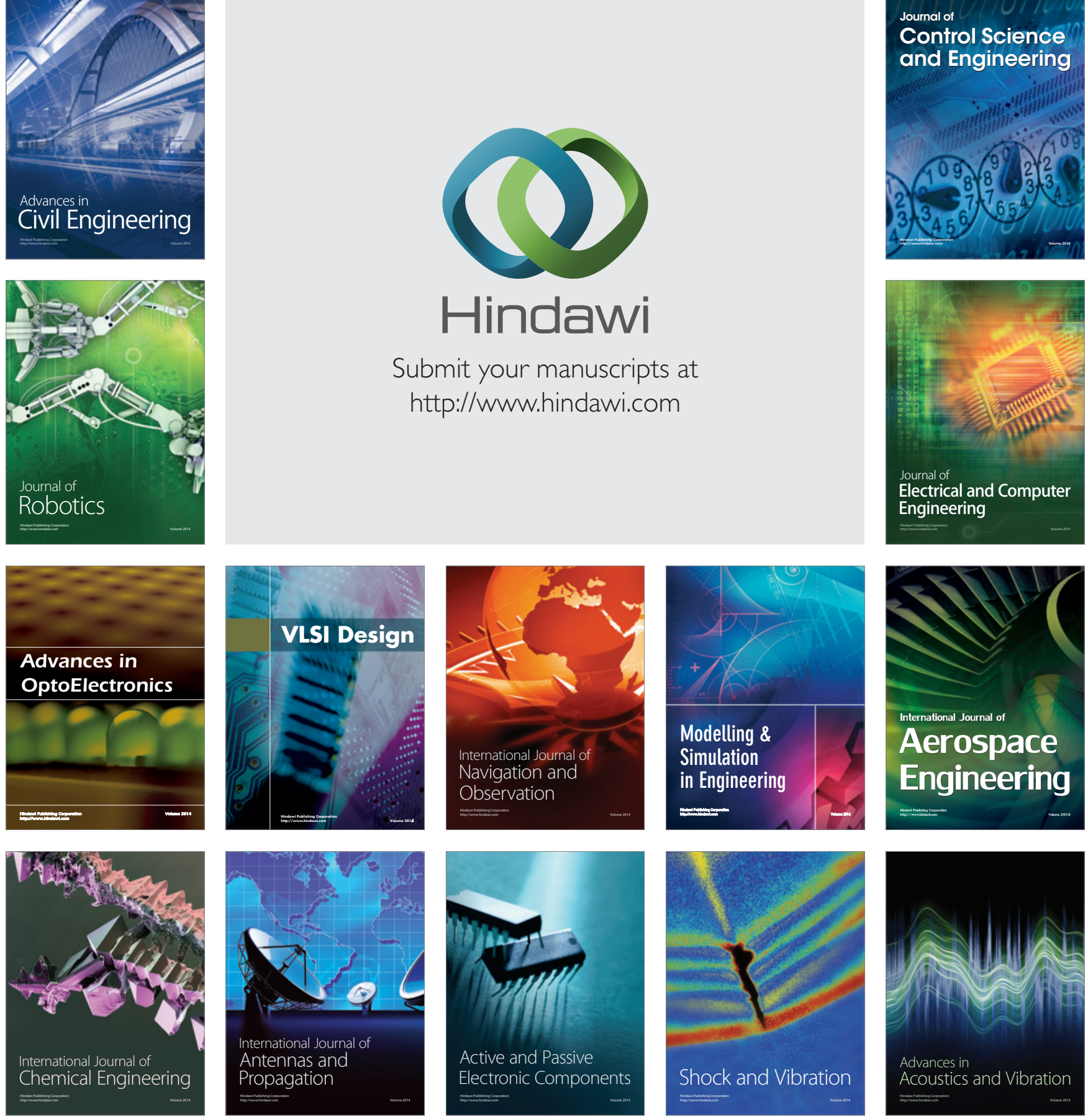